\title{
1 Role of microRNA-21 in hypertrophic cardiac
}

\section{2 remodeling}

4 Ken Watanabe ${ }^{1}$, Taro Narumi ${ }^{* 2}$, Tetsu Watanabe ${ }^{1}$, Yoichiro Otaki ${ }^{3}$, Tetsuya Takahashi ${ }^{1}$,

5 Tomonori Aono ${ }^{1}$, Jun Goto ${ }^{1}$, Taku Toshima ${ }^{1}$, Takayuki Sugai ${ }^{1}$, Masahiro Wanezaki ${ }^{1}$,

6 Daisuke Kutsuzawa ${ }^{4}$, Shigehiko Kato ${ }^{1}$, Harutoshi Tamura ${ }^{1}$, Satoshi Nishiyama ${ }^{1}$, Hiroki

$7 \quad$ Takahashi $^{3}$, Takanori Arimoto ${ }^{1}$, Tetsuro Shishido ${ }^{1}$, Masafumi Watanabe ${ }^{1,3,4}$

$9{ }^{1}$ Department of Cardiology, Pulmonology, and Nephrology, Yamagata University

10 School of Medicine, Yamagata, Japan.

112 Department of Cardiology, Internal Medicine III, Hamamatsu University School of

12 Medicine, Hamamatsu, Japan.

$13{ }^{3}$ Department of Advanced Cardiovascular Therapeutics, Yamagata University School 14 of Medicine, Yamagata, Japan.

$15{ }^{4}$ Department of Advanced Heart Rhythm Therapeutics, Yamagata University School of 16 Medicine, Yamagata, Japan.

17

18 *Address for correspondence: Taro Narumi, $\mathrm{MD}, \mathrm{PhD}$

19 E-mail: ajitaro910@gmail.com (TN) 


\section{Abstract}

21 Hypertension is a major public health problem among with aging population worldwide.

22 It causes cardiac remodeling, including hypertrophy and interstitial fibrosis, which leads

24 is associated with fibrogenesis in multiple organs, its impact on hypertrophic cardiac

remodeling in hypertension is not known. Circulating miR-21 level was higher in

patients with HHD than that in the control subjects. It also positively correlated with

upregulated in the mice hearts after angiotensin II (Ang II) infusion or transverse aortic constriction (TAC) compared with control mice. Expression level of programmed cell death 4 (PDCD4), a main target of miR-21, was significantly decreased in Ang II infused mice and TAC mice compared with control mice. Expression levels of transcriptional activator protein 1 (AP-1) and transforming growth factor- $\beta 1$ (TGF- $\beta 1$ ), which were downstream targets of PDCD4, were increased in Ang II infused mice and TAC mice compared with control mice. In vitro, mirVana-miR-21-specific inhibitor attenuated Ang II-induced PDCD4 downregulation and contributed to subsequent deactivation of AP-1/TGF- $\beta 1$ signaling pathway in neonatal rat cardiomyocytes. Thus, suppression of miR-21 prevents hypertrophic cardiac remodeling by regulating PDCD4, 
bioRxiv preprint doi: https://doi.org/10.1101/850156; this version posted November 20, 2019. The copyright holder for this preprint (which was not certified by peer review) is the author/funder, who has granted bioRxiv a license to display the preprint in perpetuity. It is made available under aCC-BY 4.0 International license.

38 AP-1, and TGF- $\beta 1$ signaling pathway. 


\section{Introduction}

40 Hypertension is a major public health concern among the elderly population worldwide.

41 It is associated with increased risk of adverse cardiovascular events [1]. An

epidemiological report indicated that $31.1 \%$ of adults in the world (1.39 billion people)

43 had hypertension in 2010 [2]. Hypertension increases the risk of developing

44 hypertension-induced organ damages, such as hypertensive heart disease (HHD),

45 hypertensive encephalopathy, and nephrosclerosis [3]. HHD is one of the most

46 important hypertension-induced organ damages [4]. According to the Framingham

47 Heart Study, $20 \mathrm{mmHg}$ increase in systolic blood pressure contributes to $56 \%$ increased risk for heart failure [5]. Furthermore, it was reported that HHD is a common pathophysiology of heart failure with preserved ejection fraction [6, 7]. Hypertension causes cardiac remodeling characterized by cardiac fibrosis, which contributes to

51 progression of heart failure [3, 4].

MicroRNAs (miRs) are small non-coding RNAs that regulate post-transcriptional gene expressions. They have been shown to play an important role in fibrogenic process

54 in multiple organs [8]. In the present study, we focused on the fibrogenic function of miR-21, which is a ubiquitously expressed miR that is reported to have a pivotal role in

56 development of tissue fibrosis [9]. Transforming growth factor- $\beta 1$ (TGF- $\beta 1$ ), a 
57 pleiotropic and multifactorial cytokine involved in many biological processes, plays a

58 crucial role in the pathogenesis of cardiac remodeling in hypertension [10]. It has been

59 demonstrated that miR-21 can promote TGF- $\beta 1$ signaling $[11,12]$. On the other hand,

60 miR-21 has been found to be upregulated by TGF- $\beta 1$ [13]. This interrelationship forms

61 a positive feedback loop, which may exacerbate the fibrogenic process. Previous studies

62 have also demonstrated the contribution of miR-21 in patients with aortic stenosis,

63 hypertrophic cardiomyopathy, and dilated cardiomyopathy [14-16]. However, the

64 impact of miR-21 on the pathogenesis of hypertrophic cardiac remodeling in

65 hypertension is still not clear.

66 We hypothesized that miR-21 deteriorates hypertrophic cardiac remodeling by

67 enhancing TGF- $\beta 1$ signaling pathway through suppressing its target gene expression. In

68 the present study, we investigated the following: (1) miR-21 expression levels in

69 patients with HHD; (2) miR-21 expression levels and its downstream signaling in

70 animal model of hypertrophic cardiac remodeling by transverse aortic constriction

71 (TAC) or angiotensin II (Ang II) infusion; (3) the function of miR-21 in cardiac

72 remodeling process in response to Ang II stimulation in vitro; (4) the therapeutic

73 potential of miR-21 inhibitor in hypertrophic cardiac remodeling in vitro. 


\section{$74 \quad$ Materials and Methods}

\section{$75 \quad$ Human studies}

76 The present study included 10 patients with HHD and 10 control patients who were

77 assessed to rule out cardiomyopathy and heart failure, and had normal cardiac function

78 (Table 1). Endomyocardial biopsies (EMBs) were collected from the patients who had

79 left ventricular hypertrophy and suspected some types of cardiomyopathy. EMBs were

80 taken from left ventricle with a total of 4 to 6 samples through the femoral arteries.

81 EMBs were analyzed in 3 HHD patients who were excluded other cardiomyopathy

82 based on EMBs and other clinical data, and 3 control patients who had transient left

83 ventricular dysfunction and suspected myocarditis but were eventually ruled out

84 cardiomyopathy. The final diagnosis of HHD were made by two expert cardiologists

85 based on angiography, echocardiographic data, clinical background, and medical

86 history. Written informed consent was obtained from all patients before the study. The protocol was performed in accordance to the Helsinki Declaration and was approved by the human investigations committee of Yamagata University School of Medicine. 
Table 1. Clinical characteristics of 10 control subjects and 10 HHD patients.

\begin{tabular}{|c|c|c|c|}
\hline Variables & $\begin{array}{l}\text { Control patients } \\
n=10\end{array}$ & $\begin{array}{l}\text { HHD patients } \\
n=10\end{array}$ & $P$ value \\
\hline Age (years old) & $61 \pm 8$ & $58 \pm 12$ & ns \\
\hline Male / Female & $6 / 4$ & $7 / 3$ & ns \\
\hline $\mathrm{BMI}\left(\mathrm{kg} / \mathrm{m}^{2}\right)$ & $23.7 \pm 1.9$ & $26.1 \pm 5.9$ & ns \\
\hline Hypertension, n (\%) & $3(30)$ & $10(100)$ & $<0.05$ \\
\hline Diabetes mellitus, n (\%) & $1(10)$ & $6(60)$ & $<0.05$ \\
\hline Dyslipidemia, n (\%) & $3(30)$ & $4(40)$ & ns \\
\hline NYHA functional class III-IV, n (\%) & $0(0)$ & $4(40)$ & $<0.05$ \\
\hline \multicolumn{4}{|l|}{ Echocardiographic data } \\
\hline LVEDD (mm) & $47 \pm 5$ & $55 \pm 9$ & $<0.05$ \\
\hline LVEF $(\%)$ & $68 \pm 6$ & $52 \pm 14$ & $<0.05$ \\
\hline IVSD (mm) & $9 \pm 2$ & $14 \pm 2$ & $<0.05$ \\
\hline LVPWD (mm) & $10 \pm 1$ & $13 \pm 2$ & $<0.05$ \\
\hline \multicolumn{4}{|l|}{ Blood examination } \\
\hline $\mathrm{eGFR}\left(\mathrm{mL} / \mathrm{min} / 1.73 \mathrm{~m}^{2}\right)$ & $92.0 \pm 18.9$ & $56.3 \pm 25.5$ & $<0.05$ \\
\hline $\mathrm{BNP}(\mathrm{pg} / \mathrm{mL})$ & $36(17-70)$ & $463(143-713)$ & $<0.05$ \\
\hline \multicolumn{4}{|l|}{ Medications } \\
\hline ACEIs and/or ARBs, n (\%) & $3(30)$ & $10(100)$ & $<0.05$ \\
\hline CCBs, n $(\%)$ & $1(10)$ & $7(70)$ & $<0.05$ \\
\hline Diuretics, n (\%) & $0(0)$ & $6(60)$ & $<0.05$ \\
\hline Statins, n (\%) & $3(30)$ & $5(50)$ & ns \\
\hline
\end{tabular}

Data are expressed as mean $\pm \mathrm{SD}$, number (percentage), or median (interquartile range).

91 ACEIs, angiotensin-converting enzyme inhibitors; ARBs, angiotensin II receptor 92 blockers; BMI, body mass index; BNP, B-type natriuretic peptide; CCBs, calcium93 channel blockers; eGFR, estimated glomerular filtration rate; HHD, hypertensive heart 94 disease; IVSD, interventricular septum diameter; LVEDD, left ventricular end-diastolic 95 diameter; LVEF, left ventricular ejection fraction; LVPWD, left ventricular posterior wall 96 diameter; NYHA, New York Heart Association. 


\section{Measurement of circulating miR-21 levels and biochemical \\ 98 assays}

99 Blood samples were collected in the early morning within 24 hours after admission,

100 centrifuged at $3000 \mathrm{~g}$ for $15 \mathrm{~min}$ at $4{ }^{\circ} \mathrm{C}$, and the obtained serum was stored at $-80^{\circ} \mathrm{C}$.

101 Circulating miRs were isolated from $300 \mu \mathrm{L}$ serum by using a NucleoSpin microRNA

102 isolation kit (TaKaRa, Otsu, Japan).

103 Serum carboxy-terminal telopeptide of type I collagen (I-CTP) concentrations were

104 determined by radioimmunoassay (Orion Diagnostica, Finland) [17]. Serum procollagen

105 type III N-terminal propeptide (P3NP) levels were measured with enzyme-linked

106 immunosorbent assay (ELISA) kit (MyBioSource, San Diego, CA, USA).

108 Animal treatment regimens

109 Hypertension-induced cardiac remodeling models were established by Ang II infusions

110 or TAC surgery $[18,19]$. Briefly, Ang II was infused with ALZET osmotic pumps $(1.5$

$111 \mathrm{mg} / \mathrm{kg} /$ day) as we previously described [18]. Cardiac function, dimension, and blood

112 pressure were assessed after 2 weeks from Ang II infusion. The mice were sacrificed by

113 intraperitoneal injection of a combination of ketamine $(1 \mathrm{~g} / \mathrm{kg})$ and xylazine $(100$

$114 \mathrm{mg} / \mathrm{kg}$ ), and the heart samples were obtained for the biochemical and histopathological 
115 study. TAC surgery was performed to induce chronic pressure overload as we

116 previously described [20]. Briefly, 8- to 10-week-old mice were anesthetized by

117 intraperitoneal injection with a mixture of ketamine $(80 \mathrm{mg} / \mathrm{kg})$ and xylazine $(8 \mathrm{mg} / \mathrm{kg})$.

118 Animals were intubated and ventilated with a rodent ventilator (Harvard Apparatus,

119 Holliston, MA, USA). The transverse aortic arch was ligated (7-0 prolene) between the

120 right innominate and left common carotid arteries with a 27 -gauge needle, and then the

121 needle was promptly removed leaving a discrete region of stenosis. Cardiac remodeling

122 was assessed after 4 weeks from surgery. All experimental procedures were performed

123 according to the animal welfare regulations of Yamagata University School of

124 Medicine, and the study protocol was approved by the Animal Subjects Committee of

125 Yamagata University School of Medicine. The investigation conformed to the Guide for

126 the Care and Use of Laboratory Animals published by the US National Institutes of

127 Health (NIH Publication, 8th Edition, 2011).

129 Neonatal rat cardiomyocyte isolation, cell culture, and

130 treatment

131 Isolation and culture of neonatal rat cardiomyocytes (NRCMs) were performed as we

132 previously described [21]. Briefly, ventricles were obtained from 1- to 2-day-old 
133 Sprague-Dawley rat pups after euthanasia by decapitation, and cardiomyocytes were

134 isolated by digestion with collagenase. Cardiomyocytes were kept in serum-

135 supplemented (10\% fatal bovine serum, FBS) Dulbecco’s Modified Eagle Medium

136 (DMEM, Thermo Fisher Scientific, MA, USA). Primary culture of cardiofibroblasts

137 were obtained as previously described [22]. Briefly, ventricles of Sprague-Dawley rat

138 pups were digested with collagenase, and resuspended in DMEM with 10\% FBS. Cells

139 were then seeded into 10 -cm culture dishes and cultured at $37^{\circ} \mathrm{C}$ for $2 \mathrm{~h}$. Unattached

140 cells were discarded, and attached cells were cultured in DMEM with 10\% FBS.

141 NRCMs were transfected with small interfering RNA (siRNA) specific for programmed

142 cell death 4 (PDCD4) (Thermo Fisher Scientific), 10-nM mirVana hsa-miR-21 specific

143 inhibitor (Thermo Fisher Scientific), or mirVana miRNA inhibitor Negative Control

144 (Thermo Fisher Scientific) using Lipofectamine 3000 Reagent (Thermo Fisher

145 Scientific) according to the manufacturer's instructions. The medium was replaced with

146 DMEM with 10\% FBS after transfection for 4h. NRCMs were stimulated with $1 \mu \mathrm{M}$

147 Ang II for 24 hours of serum starvation.

\section{Western blotting}

150 The total protein extracts were prepared with radio-immunoprecipitation assay (RIPA) 
151 buffer as we previously reported [21]. Equal amounts of protein were subjected to $10 \%$

152 SDS-PAGE and transferred to polyvinylidene difluoride membranes. The membranes

153 were probed overnight at $4{ }^{\circ} \mathrm{C}$ with the following primary antibodies: PDCD4 (Santa

154 Cruz, Dallas, TX, USA, sc-376430), c-Jun (Cell Signaling Technology, Danvers, MA,

155 USA, \#9165), TGF- $\beta 1$ (Cell Signaling Technology, \#3711), phospho-transforming

156 growth factor- $\beta$-activated kinase 1 (p-TAK1) (Cell Signaling Technology, \#4537),

157 TAK1 (Cell Signaling Technology, \#4505), $\beta$-tubulin (Cell Signaling Technology,

158 \#2146). Protein expression levels were normalized to that of $\beta$-tubulin.

160 RNA extraction and quantitative reverse transcription

161 polymerase chain reaction (qRT-PCR)

162 Total RNA was isolated from human endomyocardial biopsy specimens, mouse whole

163 heart, and NRCMs using TRIzol reagent (Thermo Fisher Scientific) as we previously

164 described [23]. For miRs screening assay, first strand cDNA of miRs was synthesized,

165 and PCR reaction was performed using a miR-X miRNA qRT-PCR SYBR Kit

166 (TaKaRa) according to the manufacturer's instructions. For other studies, first strand

167 cDNA was synthesized using a Superscript IV First-strand cDNA synthesis kit (Thermo

168 Fisher Scientific) and quantitative RT-PCR (qRT-PCR) was performed with SYBR 
169 Green Real-Time PCR Master Mixes (Thermo Fisher Scientific) according to the

170 manufacturer's instructions. Gene expressions was normalized to U6 for miR assay and

$171 \beta$-actin for other assays.

\section{Histopathological examinations}

174 Biopsy samples of human cardiomyocyte and mice heart samples were fixed with 4\%

175 formalin and embedded in paraffin. Sections of 3-5 $\mu \mathrm{m}$ thickness were stained with

176 hematoxylin-eosin (HE) or Massons's trichrome stain for histopathological analysis as

177 we previously described [20]. The extent of myocardial interstitial fibrosis was

178 evaluated using a microscope and attached software (BZ-X710; Keyence, Osaka, 179 Japan)

\section{Statistical analysis}

182 All values are expressed as mean \pm standard error of mean (SEM). Statistical differences among groups were evaluated with one-way analysis of variance (ANOVA)

184 followed by Tukey-Kramer post hoc tests. Correlations between the circulating miRs

185 levels and biomarkers of cardiac fibrosis were analyzed by using Pearson's correlation coefficient. A value of $P<0.05$ was considered statistically significant. All statistical 
bioRxiv preprint doi: https://doi.org/10.1101/850156; this version posted November 20, 2019. The copyright holder for this preprint (which was not certified by peer review) is the author/funder, who has granted bioRxiv a license to display the preprint in perpetuity. It is made available under aCC-BY 4.0 International license.

187 analyses were performed with a standard software package (JMP version 12; SAS

188 institute, Cary, NC, USA). 


\section{Results}

\section{MiRs expression levels in patients with hypertensive heart}

\section{1 disease}

192 To investigate the expression levels of fibrosis-associated miRs according to previous

193 report [24], we first measured the levels of circulating miR-21, miR-29, miR-30, and

194 miR-133 in patients with HHD. Circulating miR-21 levels were significantly increased

195 in patients with HHD compared with those of control subjects. On the other hand,

196 circulating miR-29, miR-30, and miR-133 levels were significantly decreased in

197 patients with HHD (Fig. 1A). HE and Masson's trichrome staining revealed that

198 significant cardiac hypertrophy and fibrosis was observed in the heart section from

199 patients with HHD (Fig. 1B). MiR-21 levels were significantly increased in the heart samples of patients with HHD compared with those of the normal subjects. In contrast, miR-29, miR-30, and miR-133 levels tended to be decreased in patients with HHD, but the differences were not statistically significant (Fig. 1C). We measured serum I-CTP and P3NP levels as markers of myocardial fibrosis [17, 25]. Serum I-CTP and P3NP levels were significantly higher in patients with HHD compared with those of control subjects (Fig. 1D). As shown in Fig. 1E, there were significant positive correlations between circulating miR-21 levels and serum I-CTP $(R=0.560)$ and P3NP $(R=0.477)$. 
207 However, there were no significant correlations between other miRs and I-CTP (miR-

208 29: $\mathrm{R}=-0.215 ; \mathrm{miR}-30: \mathrm{R}=-0.068 ; \mathrm{miR}-133: \mathrm{R}=0.268)$ and $\mathrm{P} 3 \mathrm{NP}(\mathrm{miR}-29: \mathrm{R}=$

$209-0.302$; miR-30: $\mathrm{R}=-0.263$; miR-133: $\mathrm{R}=-0.138$ ) levels.

211 Fig 1. Association between miRs expressions and cardiac remodeling in patients

212 with HHD.

213 (A) Circulating miRs expressions in patients with HHD ( $\mathrm{n}=10$ per group). (B)

214 Representative images and analysis of cardiac remodeling by HE and Masson's

215 trichrome staining in heart samples from HHD patients and normal subjects $(\mathrm{n}=3$ per

216 group). Scale bars $=20 \mu \mathrm{m}$. (C) Expression of miRs levels in heart samples from

217 patients with HHD ( $\mathrm{n}=3$ per group). (D) Serum I-CTP and P3NP levels in patients with

218 HHD. (E) Circulating miR-21 levels were positively correlated with serum I-CTP and

219 P3NP levels in patients with HHD. Data are expressed as mean \pm SEM. ${ }^{*} P<0.05,{ }^{* *} P<$ $220 \quad 0.01$.

224 MiR-21 expression levels were significantly increased in Ang II infused mice hearts 
225 compared with those of sham mice (Fig. 2A). Cardiac remodeling was detected by HE

226 and Masson's trichrome staining in Ang II infused mice hearts but not in sham mice

227 (Fig. 2B). Alpha smooth muscle actin ( $\alpha$-SMA) mRNA expression was significantly

228 upregulated in the Ang II infused mice hearts compared with those of the sham mice

229 (Fig. 2C). Similarly, miR-21 expression levels were significantly increased in the heart

230 of TAC mice compared with those of sham-operated mice (Fig. 2D). Cardiac

231 remodeling was also detected by HE and Masson's trichrome staining in TAC mice but

232 not in the sham-operated mice (Fig. 2E). $\alpha$-SMA mRNA expression was significantly

233 upregulated in the TAC mice hearts compared with those of the sham-operated mice

234 (Fig. 2F). Echocardiographic and hemodynamic data of Ang II infused mice and TAC

235 operated mice are shown in Table 2.

237 Fig 2. The crucial role of miR-21 in cardiac remodeling in Ang II infused and TAC

\section{8 mice models.}

239 (A) MiR-21 expression levels in Ang II infused mice ( $n=6$ per group). (B)

240 Representative images and analysis of cardiac remodeling by HE and Masson's

241 trichrome staining in left ventricular sections in Ang II infused mice hearts $(\mathrm{n}=6$ per

242 group). Scale bars $=50 \mu \mathrm{m}$. (C) $\alpha$-SMA expression in Ang II infused mice $(\mathrm{n}=6$ per 
243 group). (D) MiR-21 expression levels in the heart samples of TAC-operated mice $(\mathrm{n}=6$

244 per group). (E) Representative images and analysis of cardiac remodeling by HE and

245 Masson's trichrome staining in left ventricular sections of the TAC-operated mice

246 hearts ( $\mathrm{n}=6$ per group). Scale bars $=50 \mu \mathrm{m}$. (F) $\alpha$-SMA expression in TAC-operated

247 mice ( $\mathrm{n}=6$ per group). Data are expressed as mean \pm SEM. ${ }^{*} P<0.05,{ }^{* *} P<0.01$.

249 Table 2. Echocardiographic and hemodynamic data of Ang II infused mice and

250 TAC operated mice.

\begin{tabular}{lllll}
\hline & saline & Ang II & sham & TAC \\
\hline LVEDD, mm & $3.19 \pm 0.11$ & $2.96 \pm 0.08$ & $3.06 \pm 0.16$ & $3.13 \pm 0.15$ \\
LVESD, mm & $1.79 \pm 0.11$ & $1.58 \pm 0.09$ & $1.66 \pm 0.16$ & $2.45 \pm 0.14^{\dagger}$ \\
IVSD, mm & $0.76 \pm 0.04$ & $0.97 \pm 0.03^{* *}$ & $0.66 \pm 0.03$ & $0.99 \pm 0.02^{\dagger}$ \\
LVPWD, mm & $0.80 \pm 0.03$ & $0.94 \pm 0.02^{* *}$ & $0.72 \pm 0.03$ & $1.06 \pm 0.03^{\dagger}$ \\
FS, \% & $45.9 \pm 2.1$ & $46.9 \pm 1.6$ & $45.6 \pm 2.3$ & $22.2 \pm 2.0^{\dagger}$ \\
HR, bpm & $682 \pm 22$ & $628 \pm 16$ & $542 \pm 23$ & $554 \pm 21$ \\
SBP, mmHg & $100 \pm 4$ & $139 \pm 3^{* *}$ & & \\
DBP, mmHg & $60 \pm 6$ & $79 \pm 4^{*}$ & & \\
MBP, mmHg & $71 \pm 5$ & $99 \pm 4^{* *}$ & & \\
\hline
\end{tabular}

251 Data are expressed as mean \pm SEM; $n=6$ each; ${ }^{*} P<0.05$ and ${ }^{* *} P<0.01$ compared with 252 saline infused mice; ${ }^{\dagger} P<0.01$ compared with sham mice.

253 Ang II, angiotensin II; DBP, diastolic blood pressure; FS, fractional shortening; HR, heart

254 rate; IVSD, interventricular septum diameter; LVEDD, left ventricular end-diastolic 255 diameter; LVESD, left ventricular end-systolic diameter; LVPWD, left ventricular 256 posterior wall diameter; MBP, mean blood pressure; SBP, systolic blood pressure; TAC, 257 transverse aortic constriction.

MiR-21 has been implicated in fibrosis by suppressing its downstream genes, such as 
261 PDCD4, smad family member 7 (Smad7), phosphatase and tensin homolog (PTEN),

262 and sprouty 1 (Spry1) $[12,15,26,27]$. We examined the mRNA expression levels of

263 these targets using qRT-PCR in Ang II infused mice and TAC mice hearts. PDCD4

264 mRNA levels were significantly downregulated in Ang II infused mice hearts compared

265 with sham mice. PDCD4 mRNA levels were significantly lower in TAC mice hearts

266 than in sham mice (Fig. 3A). Smad7 mRNA levels were significantly decreased in Ang

267 II infused mice compared with sham mice, although there were no significant

268 differences in PTEN and Spry1 mRNA levels between Ang II infused mice and sham

269 mice (S1A Fig). There were no significant differences in Smad7, PTEN, and Spry1

270 mRNA levels between TAC mice and sham mice (S1B Fig).

and TAC mice hearts, we focused on PDCD4. We next investigated PDCD4 
279 (Fig. 3C). AP-1 and TGF- $\beta 1$ mRNA levels were significantly increased in the hearts of

280 TAC mice compared with those of sham mice (Fig. 3D). Moreover, PDCD4 protein

281 expression was significantly decreased in TAC mice hearts, whereas c-Jun and TGF- $\beta 1$

282 protein levels were significantly increased compared with those of sham mice (Fig. 3E).

284 Fig 3. PDCD4 expression and its downstream signaling in Ang II- and TAC-

285 induced cardiac remodeling.

286 (A) PDCD4 mRNA expression in Ang II infused and TAC-operated mice $(\mathrm{n}=6$ per

287 group). (B) AP-1 and TGF- $\beta 1$ mRNA expressions in Ang II infused mice ( $\mathrm{n}=6$ per

288 group). (C) Protein expressions of PDCD4, c-Jun, and TGF- $\beta 1$ in Ang II infused mice

289 ( $\mathrm{n}=6$ per group). (D) AP-1 and TGF- $\beta 1$ mRNA expressions in TAC-operated mice ( $\mathrm{n}$

$290=6$ per group). (E) Protein expressions of PDCD4, c-Jun, and TGF- $\beta 1$ in TAC-operated

291 mice ( $n=6$ per group). Representative images from at least six independent results are

292 shown. Data are expressed as mean \pm SEM. ${ }^{*} P<0.05$.

293

294 The impact of miR-21 in cardiomyocytes under hypertrophic

295 stimulation in vitro

296 MiR-21 expression levels were significantly increased in NRCMs under Ang II 
297 stimulation (Fig. 4A). PDCD4 mRNA expression was significantly downregulated in

298 NRCMs under Ang II stimulation (Fig. 4B). However, there were no significant

299 differences in mRNA expression levels of Smad7, PTEN, and Spry1 in NRCMs (S2A

300 Fig). The mRNA expression levels of PDCD4, Smad7, and Spry1 were significantly

301 decreased in neonatal rat cardiofibroblasts under Ang II stimulation (S2B Fig). AP-1

302 and TGF- $\beta 1$ mRNA levels were significantly upregulated in NRCMs under Ang II

303 stimulation (Fig. 4B). PDCD4 protein expressions were significantly decreased in

304 NRCMs under Ang II stimulation, whereas its targets, c-Jun and TGF- $\beta 1$ protein

305 expression levels were significantly increased (Fig. 4C).

To verify whether PDCD4 directly interacts with AP-1 and subsequent

Fig 4. MiR-21 and PDCD4 expressions in cardiomyocytes under Ang II

314 (A) MiR-21 expressions in cardiomyocytes under Ang II stimulation for $24 \mathrm{~h}(\mathrm{n}=4-6$ 
315 per group). (B) PDCD4, AP-1, and TGF- $\beta 1$ mRNA expressions in cardiomyocytes

316 under Ang II stimulation for $24 \mathrm{~h}$ ( $\mathrm{n}=4-6$ per group). (C) Protein expression levels of

317 PDCD4, c-Jun, and TGF- $\beta 1$ in cardiomyocytes under Ang II stimulation for $24 \mathrm{~h}(\mathrm{n}=$

318 4-6 per group). (D) AP-1 and TGF- $\beta 1$ mRNA expressions in cardiomyocytes

319 transfected with siPDCD4 ( $\mathrm{n}=4-6$ per group). (E) Protein expressions of PDCD4, c-

320 Jun, and TGF- $\beta 1$ in cardiomyocytes transfected with siPDCD4 ( $\mathrm{n}=4-6$ per group).

321 Representative images from at least four independent results are shown. Data are

expressed as mean \pm SEM. ${ }^{*} P<0.05$.

To clarify the direct role of miR-21 in regulating PDCD4 expressions in NRCMs,

significantly upregulated PDCD4 mRNA expressions compared with negative control

(Fig. 5A). AP-1 and TGF- $\beta 1$ mRNA expressions were significantly downregulated in

NRCMs with miR-21 inhibitor compared with those in the negative control. PDCD4

331 protein expression levels were significantly decreased under miR-21 inhibitor 
334 Fig 5. The impact of miR-21 suppression on PDCD4, AP-1, and TGF- $\beta 1$ signaling

\section{5 in cardiomyocytes.}

336 (A) Effect of miR-21 suppression on PDCD4, AP-1, and TGF- $\beta 1$ mRNA expressions in

337 cardiomyocytes ( $n=4-6$ per group). (B) Effect of miR-21 suppression on PDCD4, c-

338 Jun, and TGF- $\beta 1$ protein expressions in cardiomyocytes $(\mathrm{n}=4-6$ per group).

339 Representative images from at least four independent results are shown. Data are

expressed as mean \pm SEM. ${ }^{*} P<0.05$.

MiR-21 inhibitor attenuated Ang II-induced PDCD4 suppression (Fig. 6A). As a

were significantly suppressed by miR-21 inhibitor. PDCD4 protein expression levels

were restored by inhibiting miR-21 expressions, whereas c-Jun and TGF- $\beta 1$ protein

expression levels were significantly suppressed (Fig. 6B).

molecular for cardiac hypertrophy, in NRCMs under Ang II stimulation (Fig. 6C).

Atrial natriuretic peptide (ANP) and brain natriuretic peptide (BNP) mRNA expressions 
351 significantly suppressed the mRNA expression of ANP and BNP in NRCMs under Ang

352 II stimulation (Fig. 6D).

354 Fig 6. The impact of miR-21 suppression on cardiac remodeling under Ang II

355 stimulation.

356 (A) Effect of miR-21 suppression on PDCD4, AP-1, and TGF- $\beta 1$ mRNA expressions in

357 cardiomyocytes under Ang II stimulation for $24 \mathrm{~h}(\mathrm{n}=4-6$ per group). (B) Effect of

358 miR-21 suppression on PDCD4, c-Jun, and TGF- $\beta 1$ protein expressions in

359 cardiomyocytes under Ang II stimulation for $24 \mathrm{~h}(\mathrm{n}=4-6$ per group). (C) Effect of

360 miR-21 suppression on TAK1 and pTAK1 expressions in cardiomyocytes under Ang II

361 stimulation for $24 \mathrm{~h}(\mathrm{n}=4-6$ per group). (D) Effect of miR-21 suppression on fetal gene

expressions in cardiomyocytes under Ang II stimulation for $24 \mathrm{~h}(\mathrm{n}=4-6$ per group).

363 Representative images from at least four independent results are shown. Data are

expressed as mean \pm SEM. ${ }^{*} P<0.05$. 


\section{Discussion}

366 In the present study, we revealed the functional role of miR-21 in hypertrophic cardiac

367 remodeling. In patients with HHD, miR-21 expression levels were upregulated in the

368 heart and blood samples. Furthermore, circulating miR-21 levels were positively

369 correlated with serum markers of myocardial fibrosis. In cardiomyocytes, PDCD4

370 played a pivotal role in regulating cardiac remodeling as a target gene of miR-21 under

371 hypertrophic stimulation. Knockdown of miR-21 ameliorated AP-1 mediated TGF- $\beta 1$

372 signaling through regulating PDCD4 in cardiomyocytes. To the best of our knowledge,

373 this study is the first report to evaluate the impact of miR-21 in patients with HHD, and

374 that in cardiomyocytes in hypertrophic cardiac remodeling using in vivo and in vitro

375 experiments. A schema that includes the suggested pathway from the present study is

376 shown in Fig. 7.

Fig 7. A schema that includes the proposed pathway of miR-21 in cardiac

remodeling 
383 hypertrophic cardiac remodeling can improve the prognosis of patients with

384 hypertension. The contribution of miRs in the cardiomyopathies such as ischemic heart

385 disease, hypertrophic cardiomyopathy, and dilated cardiomyopathy has been shown [29-

386 31]. However, the impact of miR-21 as well as other miRs on the pathogenesis of HHD,

387 which is one of the most important hypertension-induced organ damages is still unclear.

388 In the present study, we showed that miR-21 expression levels were significantly

389 increased in both serum and heart samples of patients with HHD compared with normal

390 subjects. Moreover, there were significant positive correlations between circulating

391 miR-21 levels and serum markers of myocardial fibrosis. These findings support the

392 association between miR-21 and cardiac remodeling in patients with HHD.

It is well known that hypertension-derived mechanical stress induces Ang II

synthesis, and subsequent activation of nuclear AP-1 leads to the upregulation of TGF-

matrix (ECM) production, which leads to cardiac fibrosis [33]. It was reported that

TGF- $\beta 1$ was increased with advancing of fibrosis in the hearts of patients who

underwent cardiac surgery [34]. While mice with systemic overexpression of TGF- $\beta 1$ 
401 the pathogenesis of cardiac remodeling under hypertrophic stimulation. Interestingly,

402 activation of TGF- $\beta 1$ signaling increases miR-21 expressions [13]. In contrast, several

403 reports revealed that miR-21 can activate TGF- $\beta 1$ signaling $[11,12]$. This

404 interrelationship forms interesting positive feedback loop. Our results in vivo study

405 showed that miR-21 and TGF- $\beta 1$ expression levels were significantly increased in Ang

406 II infused mice and TAC mice, suggesting that an interrelationship between miR-21 and

407 TGF- $\beta 1$ may play an important role in hypertrophic cardiac remodeling.

409 fibrosis, such as lung, kidney, liver, and heart via promoting fibroblast activation [12,

$41016,37,38]$. Several reports have shown the fibrogenic function of miR-21 in fibroblasts

411 through modulation of its target genes, such as PDCD4, Smad7, PTEN, and Spry1 [12,

$41215,26,27]$. Thus, although the functional role of miR-21 in fibroblast is well known,

413 there were few studies assessing the functional role of miR-21 in cardiomyocyte. In the

414 present study, we found that Ang II significantly upregulated PDCD4 mRNA

415 expression in cardiomyocytes, although there were no significant differences in the

416 mRNA expression levels of Smad7, PTEN, and Spry1. These results suggest that

417 PDCD4 plays an important role in regulating cardiac remodeling as a target gene of

418 miR-21 under hypertrophic stimulation in cardiomyocyte. 

own transcription through miR-21/PDCD4/AP-1 pathway and exacerbate the fibrogenic process in hypertrophic cardiac remodeling.

431 However, although the effects of miR-21 inhibition on cardiac remodeling were 
suppressing miR-21/PDCD4/AP-1 feedback loop.

suppression of myocyte-derived TGF- $\beta 1$ ameliorated cardiac hypertrophy by inhibiting

441 stimulation induced TAK1 activation in cardiomyocytes. Furthermore, we showed that

442 inhibition of miR-21 expression suppressed TAK1 activity and subsequent fetal gene

443 expressions in cardiomyocytes. Remarkably, Thum et al. demonstrated that silencing of

444 miR-21 in vivo attenuated cardiac fibrosis and hypertrophy under pressure overload

445 stimulation through deactivation of cardiac fibroblast [15]. Taking our results into

446 consideration, this beneficial effect of miR-21 inhibitor in suppressing hypertrophic

447 cardiac remodeling might be attributed to not only cardiac fibroblast but also

cardiomyocyte.

We need to point out several limitations of our study. First, 3 patients with

hypertension were included in control group, although they had normal cardiac function 
455 patients with HHD. Finally, we have not evaluated the effect of miR-21 inhibitor in

456 vivo. Several studies demonstrated that inhibition of miR-21 suppressed cardiac

457 remodeling by regulating cardiac fibroblast $[15,16,26]$, although we confirmed the

458 protective effect of miR-21 inhibitor in cardiomyocyte under hypertrophic stimulation

459 in vitro. 


\section{Conclusions}

461 MiR-21 was associated with fibrogenesis in heart under hypertrophic stimulation.

462 Inhibition of miR-21 expressions prevent hypertrophic cardiac remodeling by regulating

463 PDCD4 and AP-1, TGF- $\beta 1$ signaling pathway. 


\section{Acknowledgement}

465 We thank Ms. Emiko Nishidate and Ms. Hiroko Sasaki for their excellent technical

466 assistance and comments. 


\section{References}

468 1. Worldwide trends in blood pressure from 1975 to 2015: a pooled analysis of 1479

469 population-based measurement studies with 19.1 million participants. Lancet (London,

470 England). 2017;389(10064):37-55. Epub 2016/11/20. doi: 10.1016/s0140-6736(16)31919-5.

471 PubMed PMID: 27863813; PubMed Central PMCID: PMCPMC5220163.

472 2. Mills KT, Bundy JD, Kelly TN, Reed JE, Kearney PM, Reynolds K, et al. Global Disparities

473 of Hypertension Prevalence and Control: A Systematic Analysis of Population-Based Studies

474 From 90 Countries. Circulation. 2016;134(6):441-50. Epub 2016/08/10. doi:

475 10.1161/circulationaha.115.018912. PubMed PMID: 27502908; PubMed Central PMCID:

476 PMCPMC4979614.

477 3. Williams B, Mancia G, Spiering W, Agabiti Rosei E, Azizi M, Burnier M, et al. 2018

478 ESC/ESH Guidelines for the management of arterial hypertension. Eur Heart J.

479 2018;39(33):3021-104. Epub 2018/08/31. doi: 10.1093/eurheartj/ehy339. PubMed PMID:

48030165516.

481 4. Drazner MH. The progression of hypertensive heart disease. Circulation. 2011;123(3):327-

482 34. Epub 2011/01/26. doi: 10.1161/circulationaha.108.845792. PubMed PMID: 21263005.

483 5. Haider AW, Larson MG, Franklin SS, Levy D. Systolic blood pressure, diastolic blood

484 pressure, and pulse pressure as predictors of risk for congestive heart failure in the Framingham

485 Heart Study. Annals of internal medicine. 2003;138(1):10-6. Epub 2003/01/07. PubMed PMID:

48612513039.

487 6. Runte KE, Bell SP, Selby DE, Haussler TN, Ashikaga T, LeWinter MM, et al. Relaxation

488 and the Role of Calcium in Isolated Contracting Myocardium From Patients With Hypertensive

489 Heart Disease and Heart Failure With Preserved Ejection Fraction. Circulation Heart failure.

490 2017;10(8). Epub 2017/08/09. doi: 10.1161/circheartfailure.117.004311. PubMed PMID:

491 28784688; PubMed Central PMCID: PMCPMC5567852.

492 7. Owan TE, Hodge DO, Herges RM, Jacobsen SJ, Roger VL, Redfield MM. Trends in

493 prevalence and outcome of heart failure with preserved ejection fraction. The New England

494 journal of medicine. 2006;355(3):251-9. Epub 2006/07/21. doi: 10.1056/NEJMoa052256.

495 PubMed PMID: 16855265.

496 8. Jiang X, Tsitsiou E, Herrick SE, Lindsay MA. MicroRNAs and the regulation of fibrosis. The

497 FEBS journal. 2010;277(9):2015-21. Epub 2010/04/24. doi: 10.1111/j.1742-4658.2010.07632.x.

498 PubMed PMID: 20412055; PubMed Central PMCID: PMCPMC2963651.

499 9. Huang Y, He Y, Li J. MicroRNA-21: a central regulator of fibrotic diseases via various

500 targets. Curr Pharm Des. 2015;21(17):2236-42. Epub 2014/12/30. doi:

501 10.2174/1381612820666141226095701. PubMed PMID: 25541205. 
502 10. Dobaczewski M, Chen W, Frangogiannis NG. Transforming growth factor (TGF)-beta

503 signaling in cardiac remodeling. Journal of molecular and cellular cardiology. 2011;51(4):600-6.

504 Epub 2010/11/10. doi: 10.1016/j.yjmcc.2010.10.033. PubMed PMID: 21059352; PubMed

505 Central PMCID: PMCPMC3072437.

506 11. Liu RH, Ning B, Ma XE, Gong WM, Jia TH. Regulatory roles of microRNA-21 in fibrosis

507 through interaction with diverse pathways (Review). Molecular medicine reports.

508 2016;13(3):2359-66. Epub 2016/02/06. doi: 10.3892/mmr.2016.4834. PubMed PMID:

50926846276.

510 12. Sun Q, Miao J, Luo J, Yuan Q, Cao H, Su W, et al. The feedback loop between miR-21,

511 PDCD4 and AP-1 functions as a driving force for renal fibrogenesis. J Cell Sci. 2018;131(6).

512 Epub 2018/01/24. doi: 10.1242/jcs.202317. PubMed PMID: 29361523.

513 13. Davis BN, Hilyard AC, Lagna G, Hata A. SMAD proteins control DROSHA-mediated

514 microRNA maturation. Nature. 2008;454(7200):56-61. Epub 2008/06/13. doi:

515 10.1038/nature07086. PubMed PMID: 18548003; PubMed Central PMCID:

516 PMCPMC2653422.

517 14. Fang L, Ellims AH, Moore XL, White DA, Taylor AJ, Chin-Dusting J, et al. Circulating

518 microRNAs as biomarkers for diffuse myocardial fibrosis in patients with hypertrophic

519 cardiomyopathy. Journal of translational medicine. 2015;13:314. Epub 2015/09/26. doi:

520 10.1186/s12967-015-0672-0. PubMed PMID: 26404540; PubMed Central PMCID:

521 PMCPMC4581079.

522 15. Thum T, Gross C, Fiedler J, Fischer T, Kissler S, Bussen M, et al. MicroRNA-21 contributes

523 to myocardial disease by stimulating MAP kinase signalling in fibroblasts. Nature.

524 2008;456(7224):980-4. Epub 2008/12/02. doi: 10.1038/nature07511. PubMed PMID:

52519043405.

526 16. Lorenzen JM, Schauerte C, Hubner A, Kolling M, Martino F, Scherf K, et al. Osteopontin is

527 indispensible for AP1-mediated angiotensin II-related miR-21 transcription during cardiac

528 fibrosis. Eur Heart J. 2015;36(32):2184-96. Epub 2015/04/23. doi: 10.1093/eurheartj/ehv109.

529 PubMed PMID: 25898844; PubMed Central PMCID: PMCPMC4543785.

530 17. Kitahara T, Takeishi Y, Arimoto T, Niizeki T, Koyama Y, Sasaki T, et al. Serum carboxy-

531 terminal telopeptide of type I collagen (ICTP) predicts cardiac events in chronic heart failure

532 patients with preserved left ventricular systolic function. Circulation journal : official journal of

533 the Japanese Circulation Society. 2007;71(6):929-35. Epub 2007/05/29. PubMed PMID:

53417526992.

535 18. Takahashi T, Shishido T, Kinoshita D, Watanabe K, Toshima T, Sugai T, et al. Cardiac

536 Nuclear High-Mobility Group Box 1 Ameliorates Pathological Cardiac Hypertrophy by

537 Inhibiting DNA Damage Response. JACC Basic to translational science. 2019;4(2):234-47. Epub 

PMCID: PMCPMC6488753.

540 19. Carnevale D, Mascio G, D'Andrea I, Fardella V, Bell RD, Branchi I, et al. Hypertension

541 induces brain beta-amyloid accumulation, cognitive impairment, and memory deterioration

542 through activation of receptor for advanced glycation end products in brain vasculature.

543 Hypertension. 2012;60(1):188-97. Epub 2012/05/23. doi:

544 10.1161/hypertensionaha.112.195511. PubMed PMID: 22615109; PubMed Central PMCID:

545 PMCPMC3530195.

546 20. Netsu S, Shishido T, Kitahara T, Honda Y, Funayama A, Narumi T, et al. Midkine

547 exacerbates pressure overload-induced cardiac remodeling. Biochem Biophys Res Commun.

548 2014;443(1):205-10. Epub 2013/12/03. doi: 10.1016/j.bbrc.2013.11.083. PubMed PMID:

54924291499.

550 21. Otaki Y, Takahashi H, Watanabe T, Funayama A, Netsu S, Honda Y, et al. HECT-Type

551 Ubiquitin E3 Ligase ITCH Interacts With Thioredoxin-Interacting Protein and Ameliorates

552 Reactive Oxygen Species-Induced Cardiotoxicity. J Am Heart Assoc. 2016;5(1). doi:

553 10.1161/JAHA.115.002485. PubMed PMID: 26796253; PubMed Central PMCID:

554 PMCPMC4859366.

555 22. Song J, Zhu Y, Li J, Liu J, Gao Y, Ha T, et al. Pellino1-mediated TGF-beta1 synthesis

556 contributes to mechanical stress induced cardiac fibroblast activation. Journal of molecular and

557 cellular cardiology. 2015;79:145-56. Epub 2014/12/03. doi: 10.1016/j.yjmcc.2014.11.006.

558 PubMed PMID: 25446187.

559 23. Takahashi H, Takeishi Y, Seidler T, Arimoto T, Akiyama H, Hozumi Y, et al. Adenovirus-

560 mediated overexpression of diacylglycerol kinase-zeta inhibits endothelin-1-induced

561 cardiomyocyte hypertrophy. Circulation. 2005;111(12):1510-6. Epub 2005/03/23. doi:

562 10.1161/01.Cir.0000159339.00703.22. PubMed PMID: 15781737.

563 24. van Rooij E, Olson EN. Searching for miR-acles in cardiac fibrosis. Circ Res.

564 2009;104(2):138-40. Epub 2009/01/31. doi: 10.1161/circresaha.108.192492. PubMed PMID:

565 19179664; PubMed Central PMCID: PMCPMC2747251.

566 25. Mansour IN, Bress AP, Groo V, Ismail S, Wu G, Patel SR, et al. Circulating Procollagen

567 Type III N-Terminal Peptide and Mortality Risk in African Americans With Heart Failure.

568 Journal of cardiac failure. 2016;22(9):692-9. Epub 2016/01/02. doi:

569 10.1016/j.cardfail.2015.12.016. PubMed PMID: 26721774; PubMed Central PMCID:

570 PMCPMC4917490.

571 26. Yuan J, Chen H, Ge D, Xu Y, Xu H, Yang Y, et al. Mir-21 Promotes Cardiac Fibrosis After

572 Myocardial Infarction Via Targeting Smad7. Cellular physiology and biochemistry : international

573 journal of experimental cellular physiology, biochemistry, and pharmacology. 2017;42(6):2207- 
19. Epub 2017/08/18. doi: 10.1159/000479995. PubMed PMID: 28817807. response to murine myocardial infarction: miR-21 regulates fibroblast metalloprotease- 2 via phosphatase and tensin homologue. Cardiovasc Res. 2009;82(1):21-9. Epub 2009/01/17. doi: 10.1093/cvr/cvp015. PubMed PMID: 19147652; PubMed Central PMCID: PMCPMC2652741. 28. Weber KT, Sun Y, Gerling IC, Guntaka RV. Regression of Established Cardiac Fibrosis in

580 Hypertensive Heart Disease. American journal of hypertension. 2017;30(11):1049-52. Epub 2017/04/06. doi: 10.1093/ajh/hpx054. PubMed PMID: 28379281. 29. Li X, Yang Y, Wang L, Qiao S, Lu X, Wu Y, et al. Plasma miR-122 and miR-3149 Potentially Novel Biomarkers for Acute Coronary Syndrome. PLoS One. 2015;10(5):e0125430. Epub 2015/05/02. doi: 10.1371/journal.pone.0125430. PubMed PMID: 25933289; PubMed Central PMCID: PMCPMC4416808. 30. Kuster DW, Mulders J, Ten Cate FJ, Michels M, Dos Remedios CG, da Costa Martins PA, et al. MicroRNA transcriptome profiling in cardiac tissue of hypertrophic cardiomyopathy patients with MYBPC3 mutations. Journal of molecular and cellular cardiology. 2013;65:59-66. Epub 2013/10/03. doi: 10.1016/j.yjmcc.2013.09.012. PubMed PMID: 24083979. 31. Zhou Q, Schotterl S, Backes D, Brunner E, Hahn JK, Ionesi E, et al. Inhibition of miR-208b improves cardiac function in titin-based dilated cardiomyopathy. Int J Cardiol. 2017;230:634-41. Epub 2017/01/10. doi: 10.1016/j.ijcard.2016.12.171. PubMed PMID: 28065693.

593 32. Rosenkranz S. TGF-beta1 and angiotensin networking in cardiac remodeling. Cardiovasc 594 Res. 2004;63(3):423-32. Epub 2004/07/28. doi: 10.1016/j.cardiores.2004.04.030. PubMed 595 PMID: 15276467.

596 33. Weber KT, Sun Y, Bhattacharya SK, Ahokas RA, Gerling IC. Myofibroblast-mediated mechanisms of pathological remodelling of the heart. Nature reviews Cardiology. 2013;10(1):1526. Epub 2012/12/05. doi: 10.1038/nrcardio.2012.158. PubMed PMID: 23207731. 34. Hein S, Arnon E, Kostin S, Schonburg M, Elsasser A, Polyakova V, et al. Progression from

600 compensated hypertrophy to failure in the pressure-overloaded human heart: structural 601 deterioration and compensatory mechanisms. Circulation. 2003;107(7):984-91. Epub 602 2003/02/26. PubMed PMID: 12600911.

603 35. Rosenkranz S, Flesch M, Amann K, Haeuseler C, Kilter H, Seeland U, et al. Alterations of 604 beta-adrenergic signaling and cardiac hypertrophy in transgenic mice overexpressing TGF605 beta(1). American journal of physiology Heart and circulatory physiology. 2002;283(3):H1253606 62. Epub 2002/08/16. doi: 10.1152/ajpheart.00578.2001. PubMed PMID: 12181157.

607 36. Schultz Jel J, Witt SA, Glascock BJ, Nieman ML, Reiser PJ, Nix SL, et al. TGF-beta1 608 mediates the hypertrophic cardiomyocyte growth induced by angiotensin II. J Clin Invest. 609 2002;109(6):787-96. Epub 2002/03/20. doi: 10.1172/jci14190. PubMed PMID: 11901187; 
611 37. Sun NN, Yu CH, Pan MX, Zhang Y, Zheng BJ, Yang QJ, et al. Mir-21 Mediates the

612 Inhibitory Effect of Ang (1-7) on AngII-induced NLRP3 Inflammasome Activation by Targeting

613 Spry1 in lung fibroblasts. Scientific reports. 2017;7(1):14369. Epub 2017/11/01. doi:

614 10.1038/s41598-017-13305-3. PubMed PMID: 29084974; PubMed Central PMCID:

615 PMCPMC5662719.

616 38. Zhang Z, Zha Y, Hu W, Huang Z, Gao Z, Zang Y, et al. The autoregulatory feedback loop of

617 microRNA-21/programmed cell death protein 4/activation protein-1 (MiR-21/PDCD4/AP-1)

618 as a driving force for hepatic fibrosis development. J Biol Chem. 2013;288(52):37082-93. Epub

619 2013/11/08. doi: 10.1074/jbc.M113.517953. PubMed PMID: 24196965; PubMed Central

620 PMCID: PMCPMC3873564.

621 39. Yang HS, Knies JL, Stark C, Colburn NH. Pdcd4 suppresses tumor phenotype in JB6 cells

622 by inhibiting AP-1 transactivation. Oncogene. 2003;22(24):3712-20. Epub 2003/06/13. doi:

623 10.1038/sj.onc.1206433. PubMed PMID: 12802278.

624 40. Talotta F, Cimmino A, Matarazzo MR, Casalino L, De Vita G, D'Esposito M, et al. An

625 autoregulatory loop mediated by miR-21 and PDCD4 controls the AP-1 activity in RAS

626 transformation. Oncogene. 2009;28(1):73-84. Epub 2008/10/14. doi: 10.1038/onc.2008.370.

627 PubMed PMID: 18850008.

628 41. Pellman J, Zhang J, Sheikh F. Myocyte-fibroblast communication in cardiac fibrosis and

629 arrhythmias: Mechanisms and model systems. Journal of molecular and cellular cardiology.

630 2016;94:22-31. Epub 2016/03/22. doi: 10.1016/j.yjmcc.2016.03.005. PubMed PMID:

631 26996756; PubMed Central PMCID: PMCPMC4861678.

632 42. Takahashi N, Calderone A, Izzo NJ, Jr., Maki TM, Marsh JD, Colucci WS. Hypertrophic

633 stimuli induce transforming growth factor-beta 1 expression in rat ventricular myocytes. J Clin

634 Invest. 1994;94(4):1470-6. Epub 1994/10/01. doi: 10.1172/jci117485. PubMed PMID:

635 7929822; PubMed Central PMCID: PMCPMC295284.

636 43. Gray MO, Long CS, Kalinyak JE, Li HT, Karliner JS. Angiotensin II stimulates cardiac

637 myocyte hypertrophy via paracrine release of TGF-beta 1 and endothelin-1 from fibroblasts.

638 Cardiovasc Res. 1998;40(2):352-63. Epub 1999/01/20. doi: 10.1016/s0008-6363(98)00121-7.

639 PubMed PMID: 9893729.

640 44. Koitabashi N, Danner T, Zaiman AL, Pinto YM, Rowell J, Mankowski J, et al. Pivotal role of

641 cardiomyocyte TGF-beta signaling in the murine pathological response to sustained pressure

642 overload. J Clin Invest. 2011;121(6):2301-12. Epub 2011/05/04. doi: 10.1172/jci44824.

643 PubMed PMID: 21537080; PubMed Central PMCID: PMCPMC3104748.

644

645 


\section{Supporting information}

647 S1 Fig. Smad7, PTEN, and Spry1 mRNA levels in Ang II infused and TAC mice.

648 (A) Smad7, PTEN, and Spry1 mRNA levels in Ang II infused mice compared with

649 those of saline infused mice ( $\mathrm{n}=6$ per group). (B) Smad7, PTEN, and Spry1 mRNA

650 levels in TAC mice compared with those of sham mice $(n=6$ per group). Data are

651 expressed as mean \pm SEM. ${ }^{*} P<0.05$.

652

653 S2 Fig. The differences in the expression levels of miR-21 targets between

654 cardiomyocytes and cardiofibroblasts.

655 (A) The mRNA expressions of Smad7, PTEN, and Spry1 after treatment with vehicle or

656 Ang II for $24 \mathrm{~h}$ in NRCMs ( $\mathrm{n}=4-6$ per group). (B) The mRNA expressions of PDCD4,

657 Smad7, PTEN, and Spry1 after treatment with vehicle or Ang II for $24 \mathrm{~h}$ in

658 cardiofibroblasts ( $\mathrm{n}=4-6$ per group). Data are expressed as mean \pm SEM. ${ }^{*} P<0.05$. 
Fig. 1

A

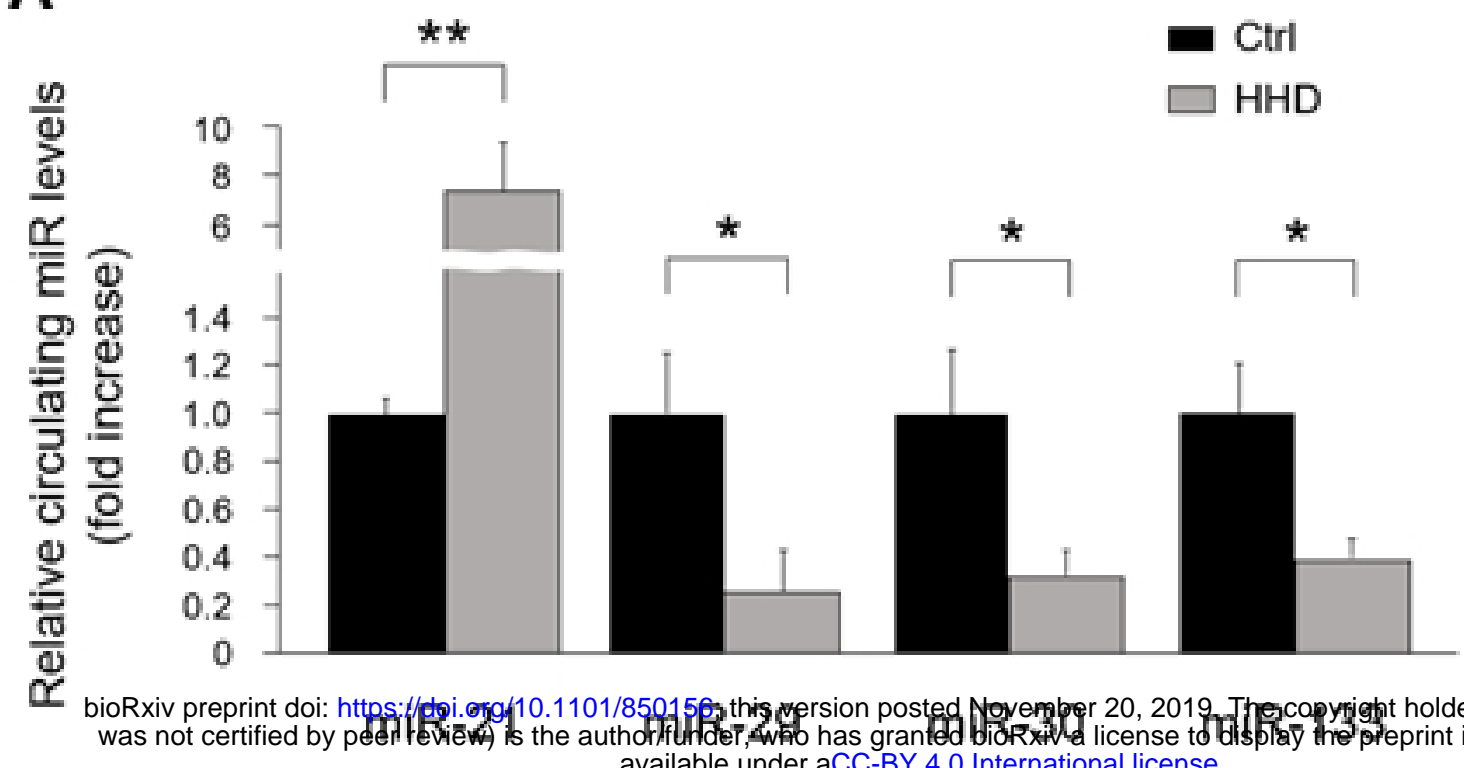
available under aCC-BY 4.0 International license.

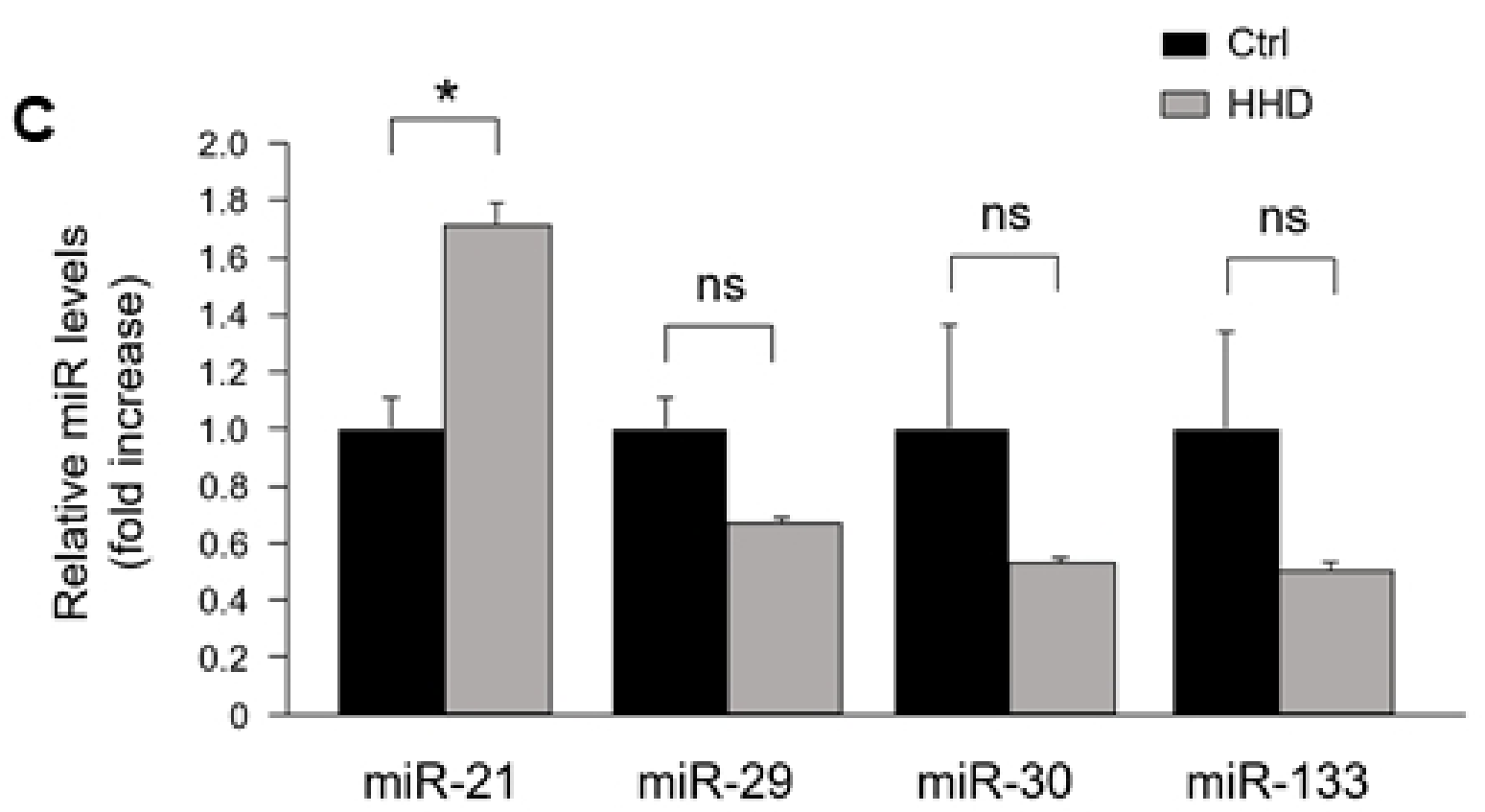

D

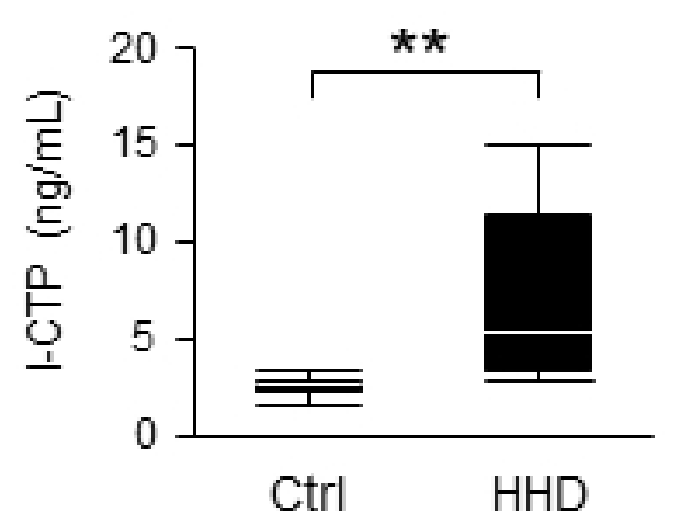

E
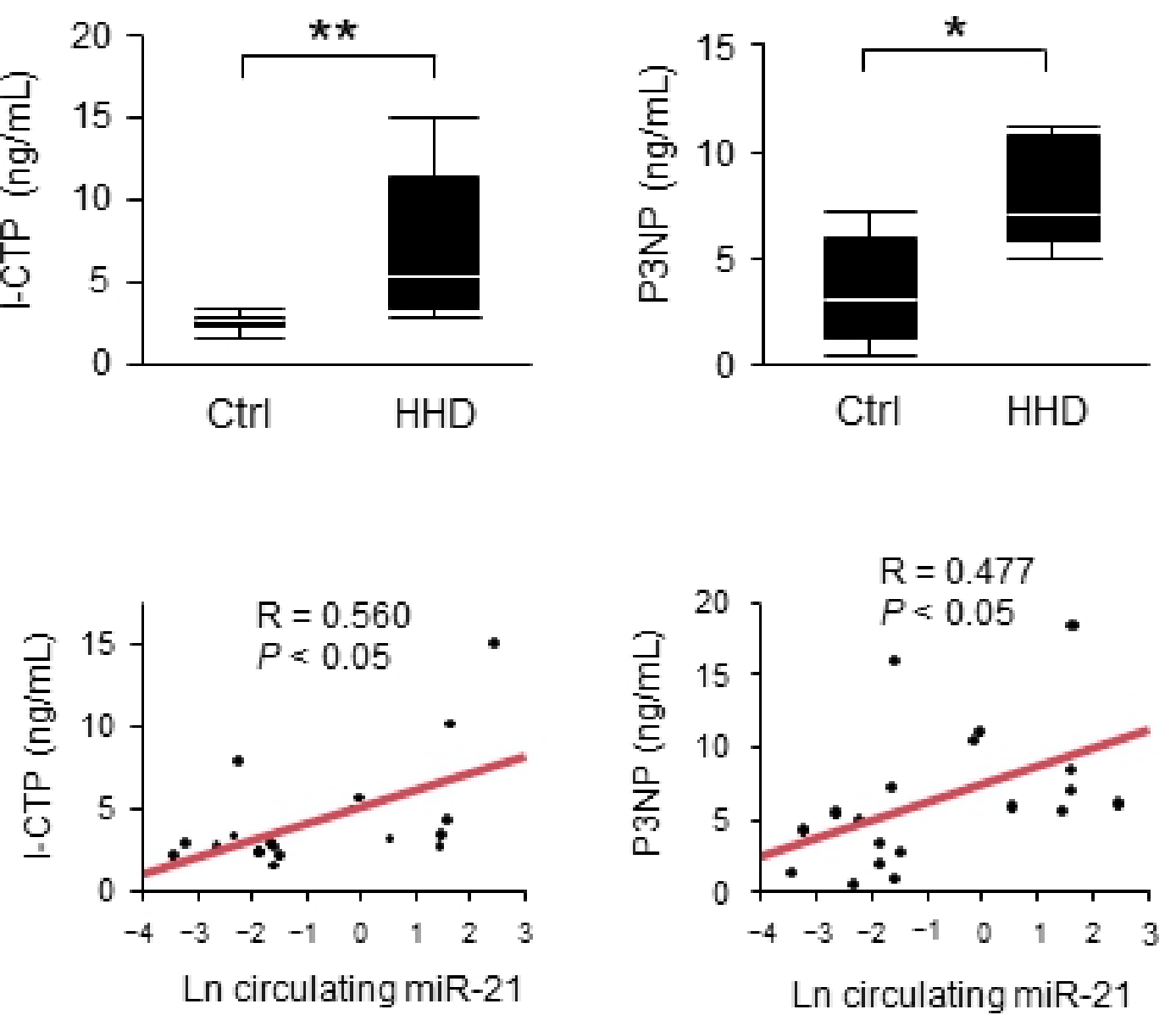

B
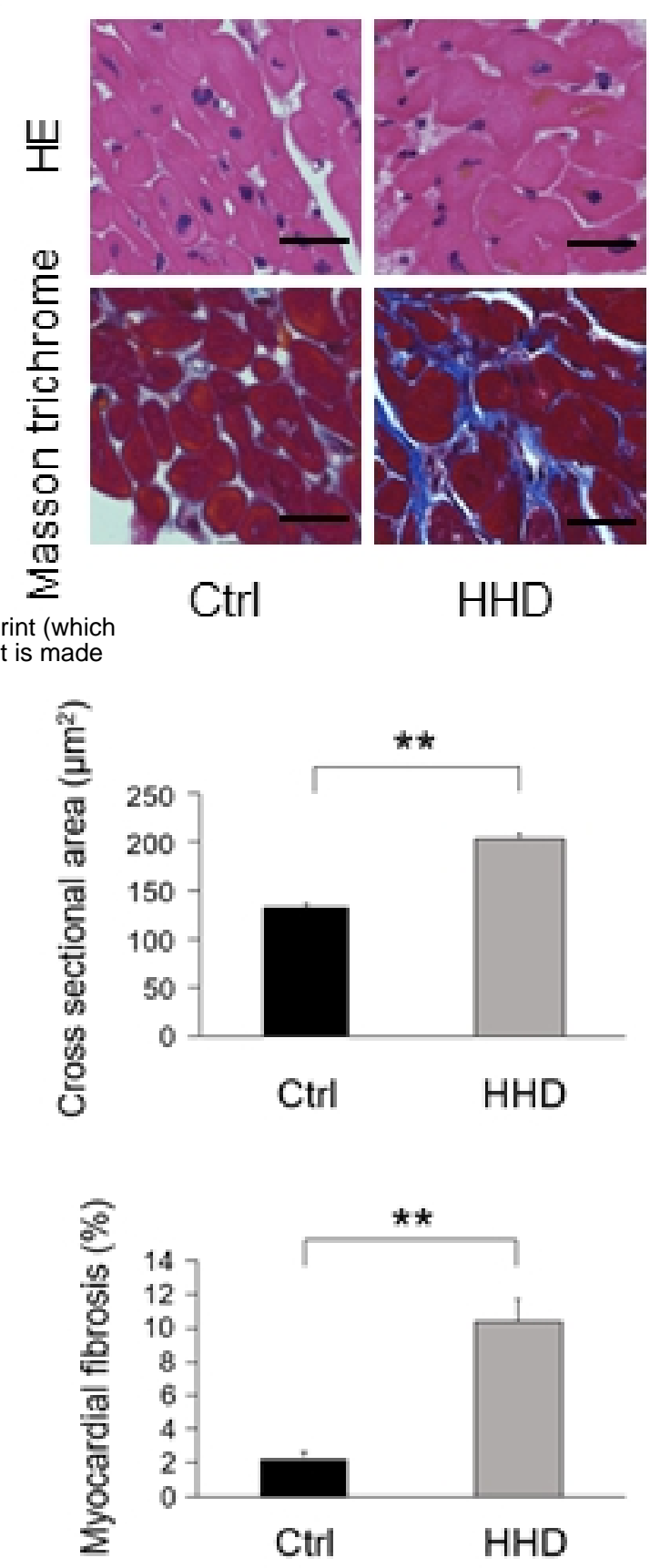

Fig. 1 
Fig. 2

A

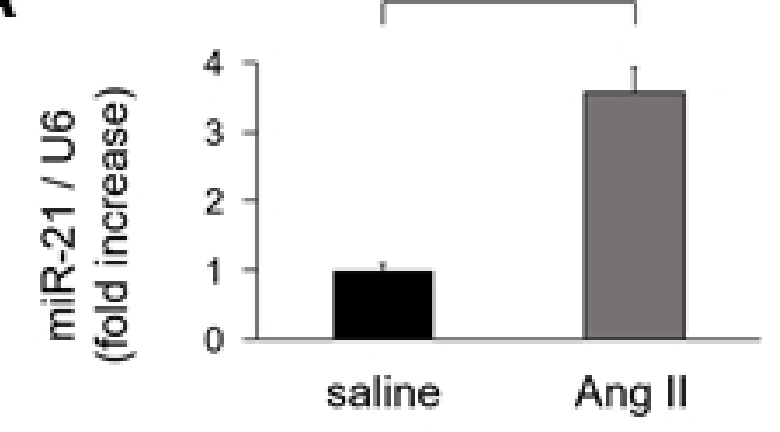

C

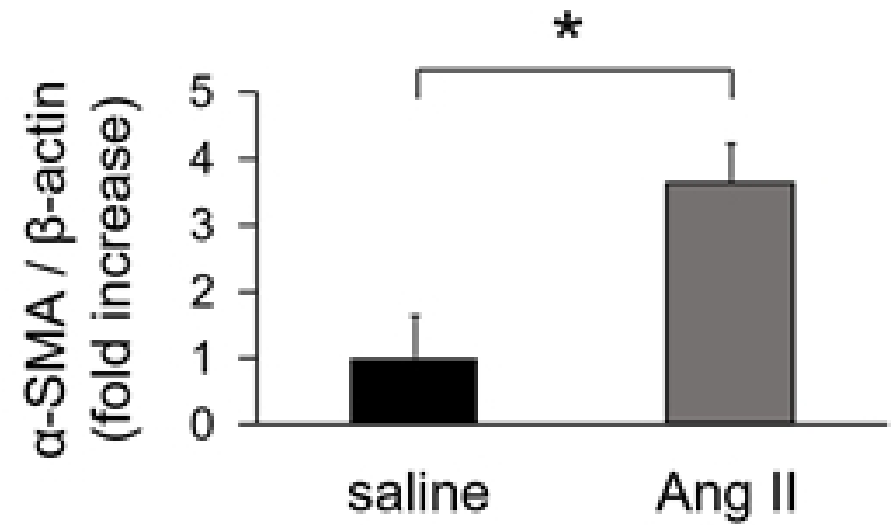

B

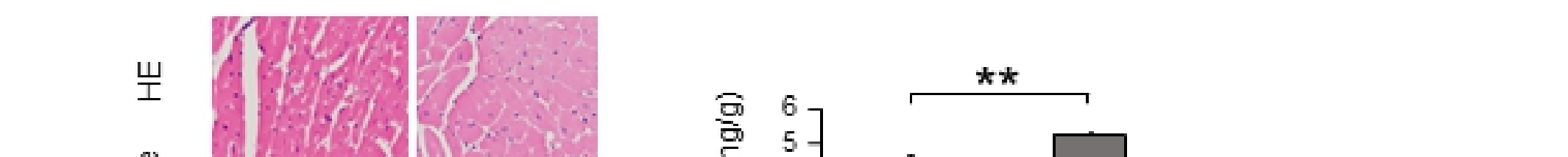

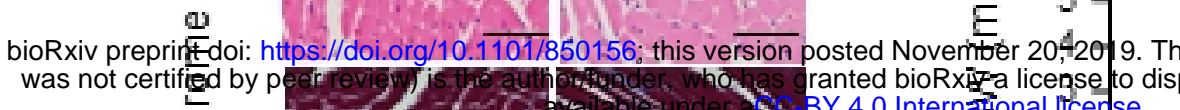
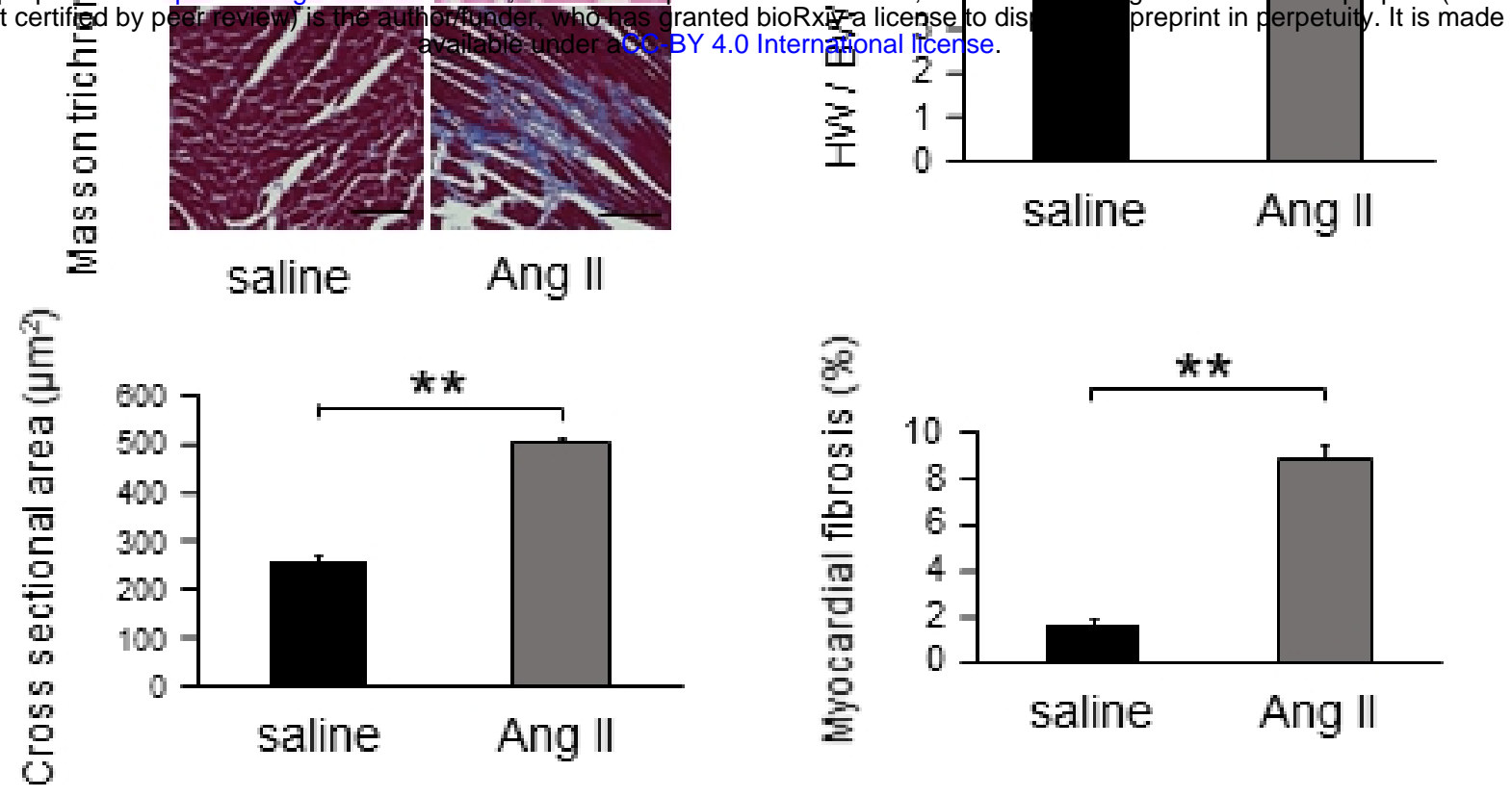

D

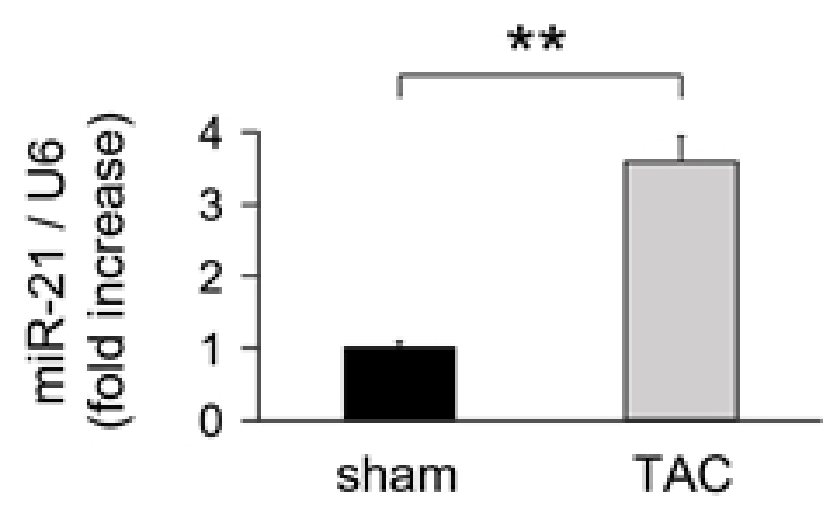

F

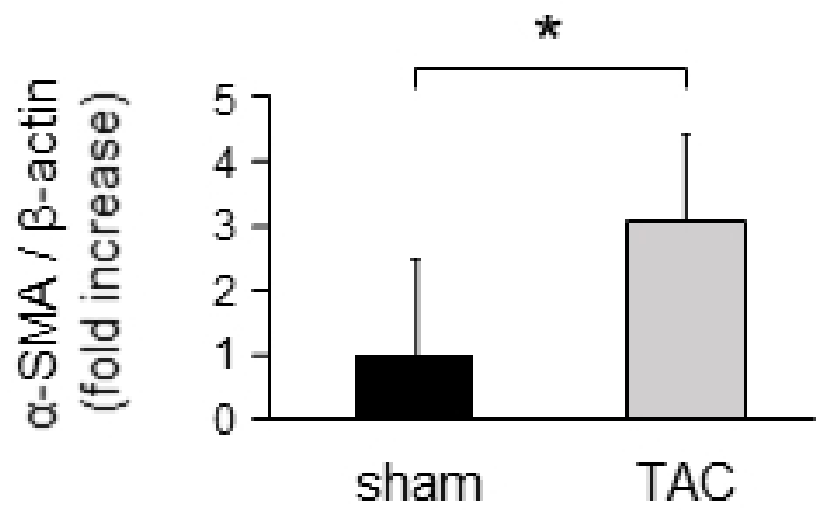

E
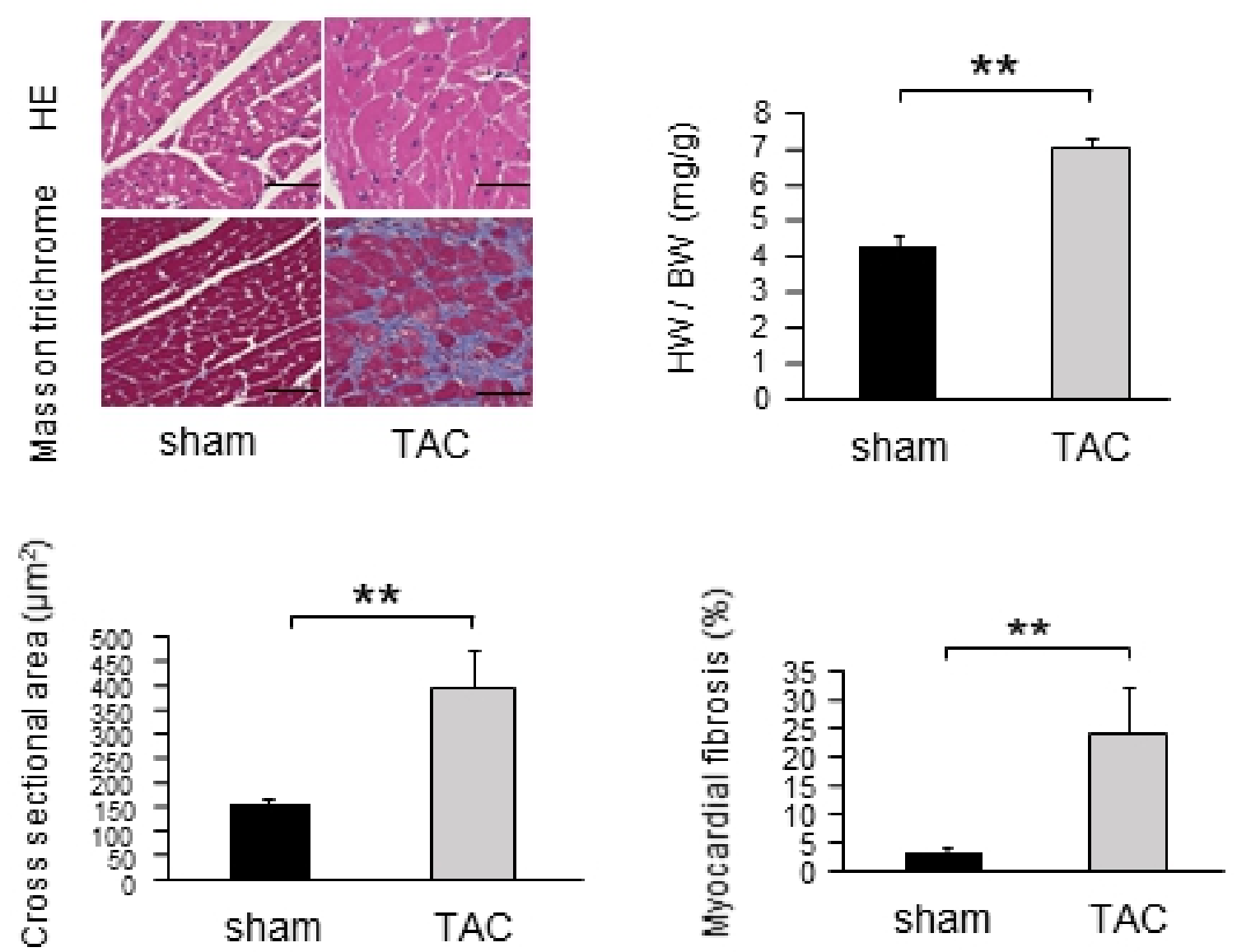

Fig. 2 
Fig. 3

A

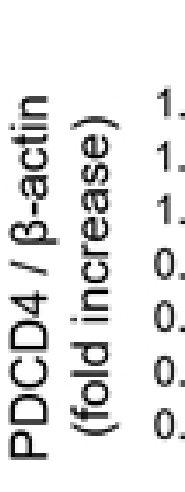
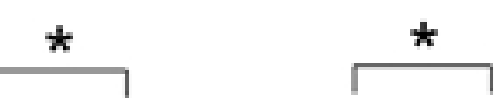

$\square$ TAC

bioRxiv preprint doi: https://doi.org/10.1101/850156; this version posted November 20, 2019. The copyright holder for this prepri was not certified by peer review) is the author/funder, who has granted bioRxiv a license to

C

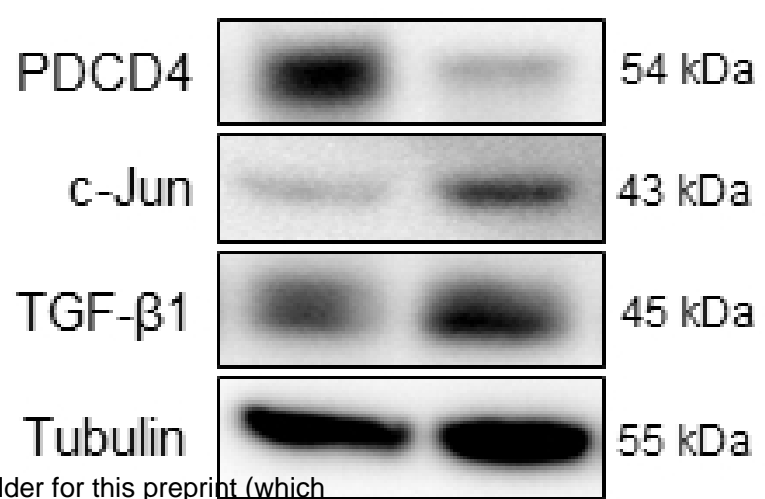

saline Ang II

B

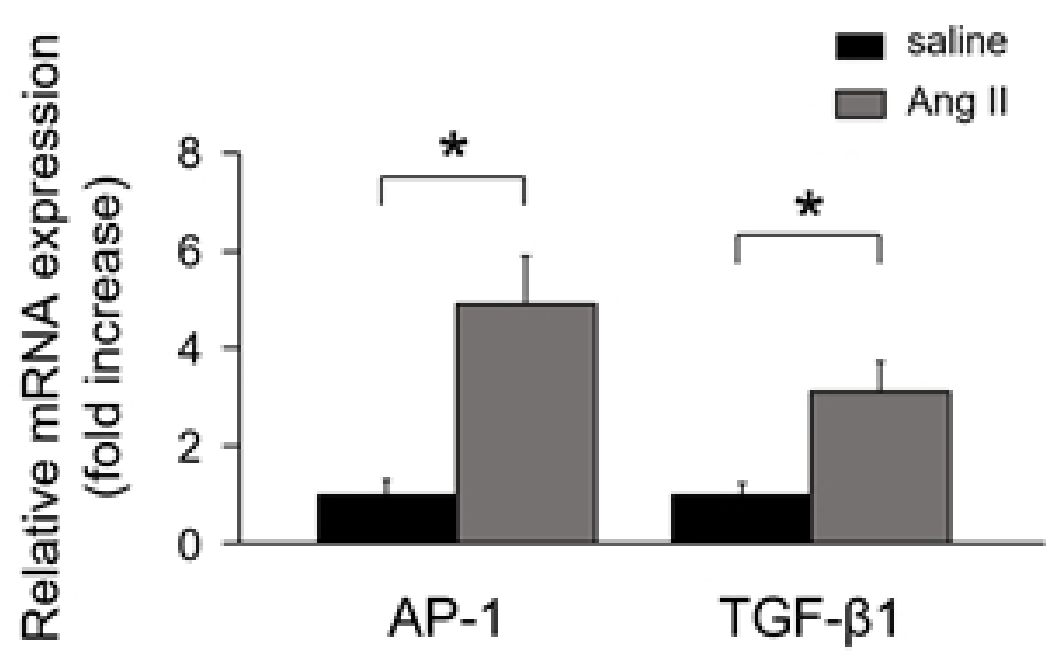

D

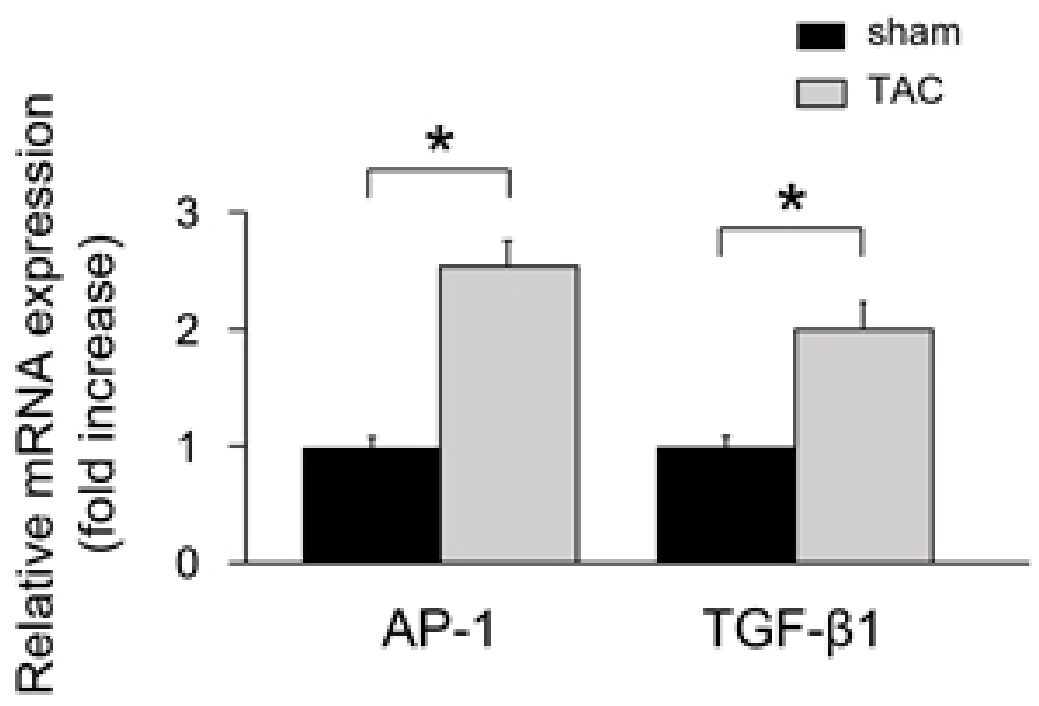

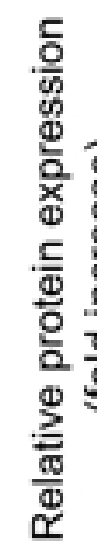

caline

$\square$ Ang II

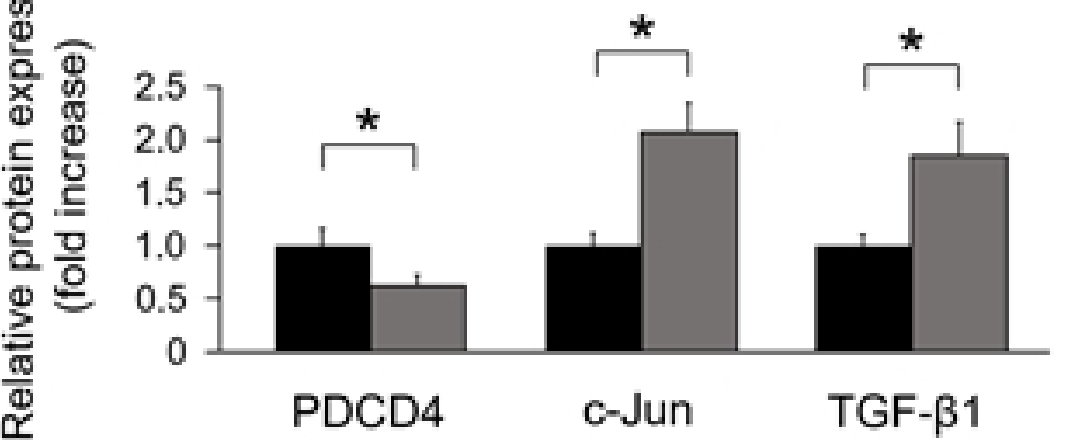

E

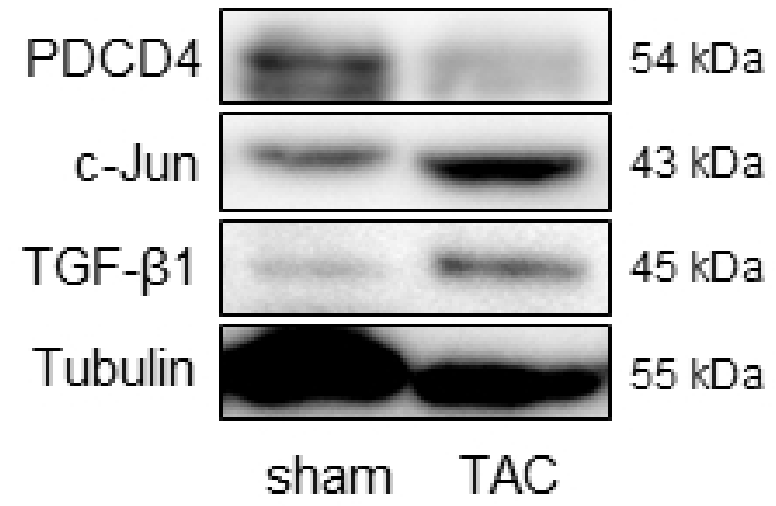

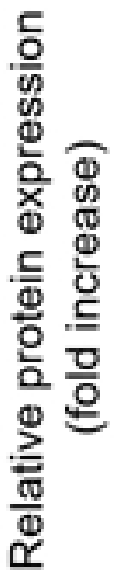

$\square$ TAC

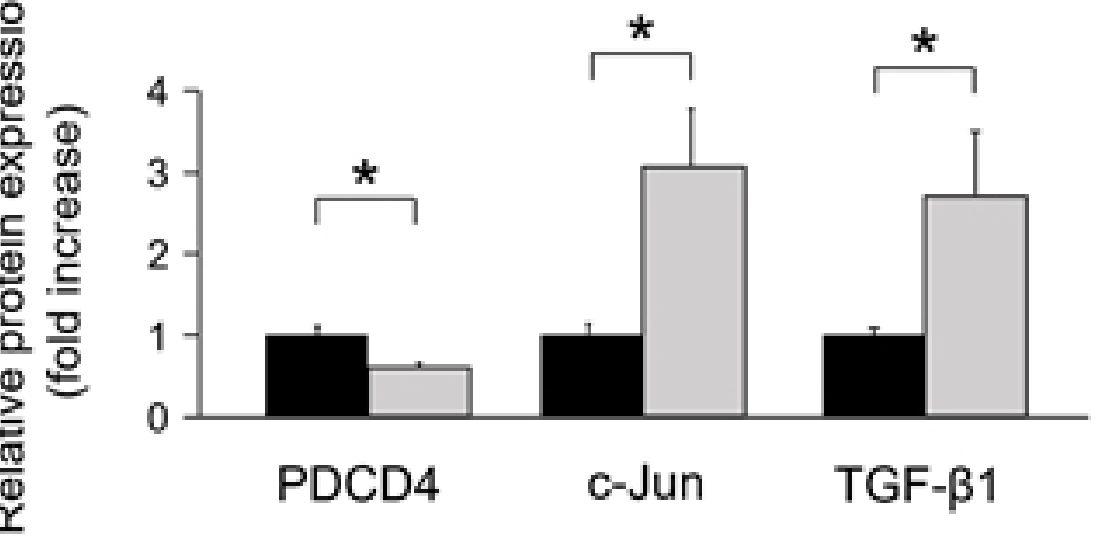

Fig. 3 
Fig. 4
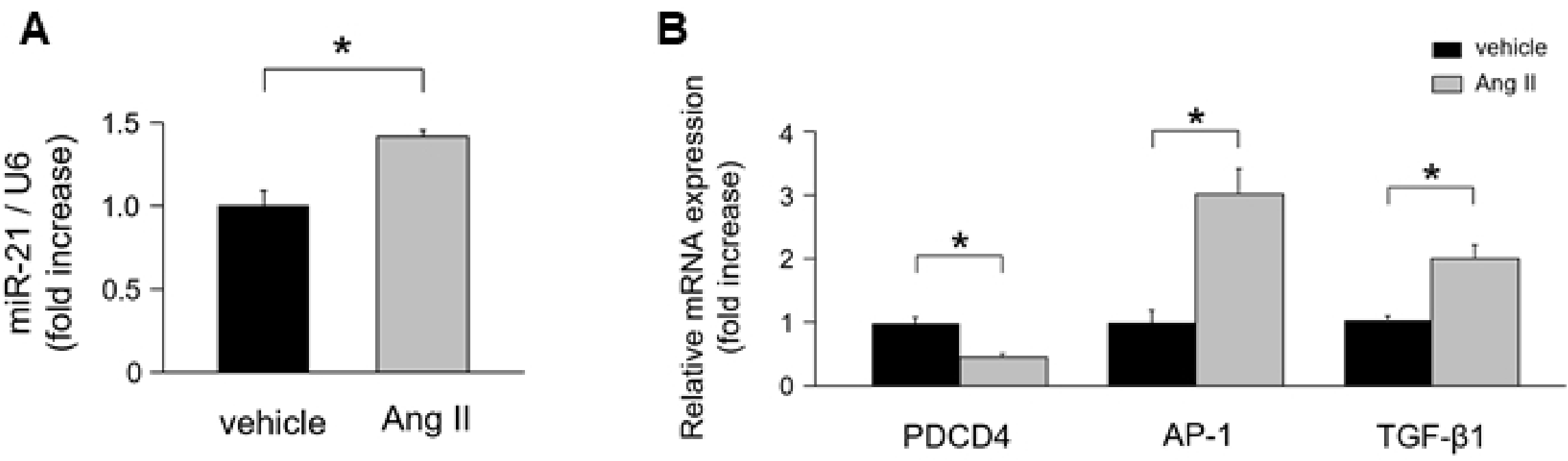

bioRxiv preprint doi: https://doi.org/10.1101/850156; this version posted November 20, 2019. The copyright holder for this preprint (which

C
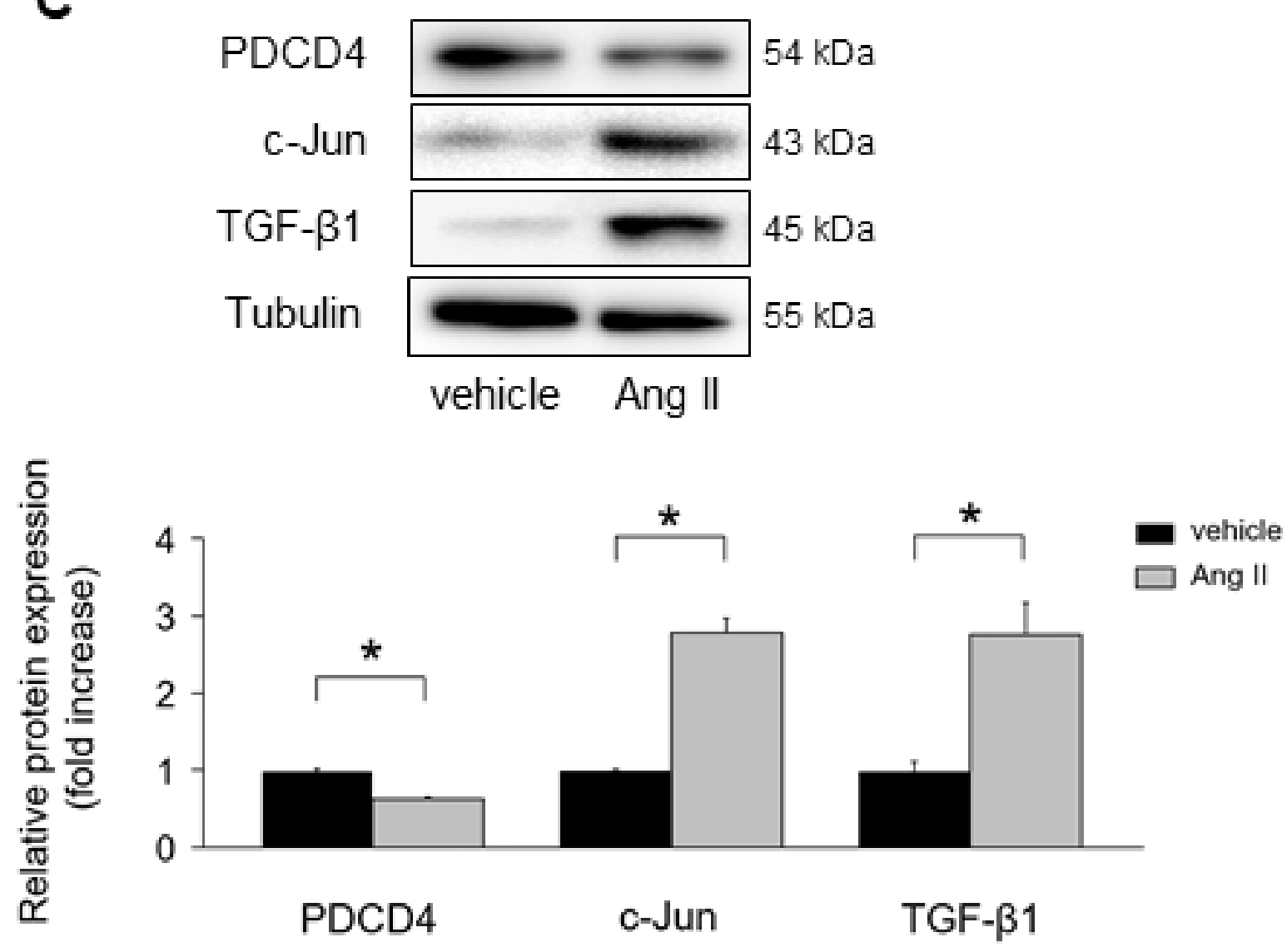

D

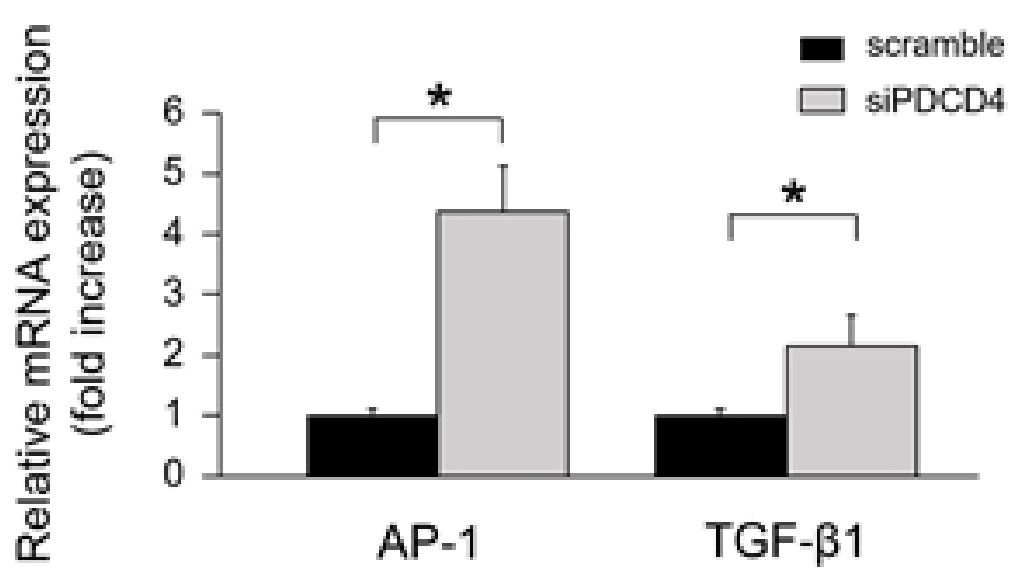

E

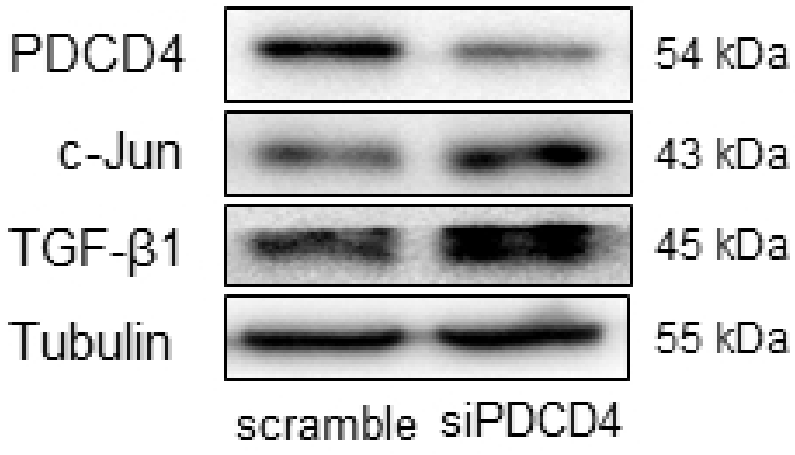

음
- scramble $\square$ siPDCD4

Fig. 4 
Fig. 5

A

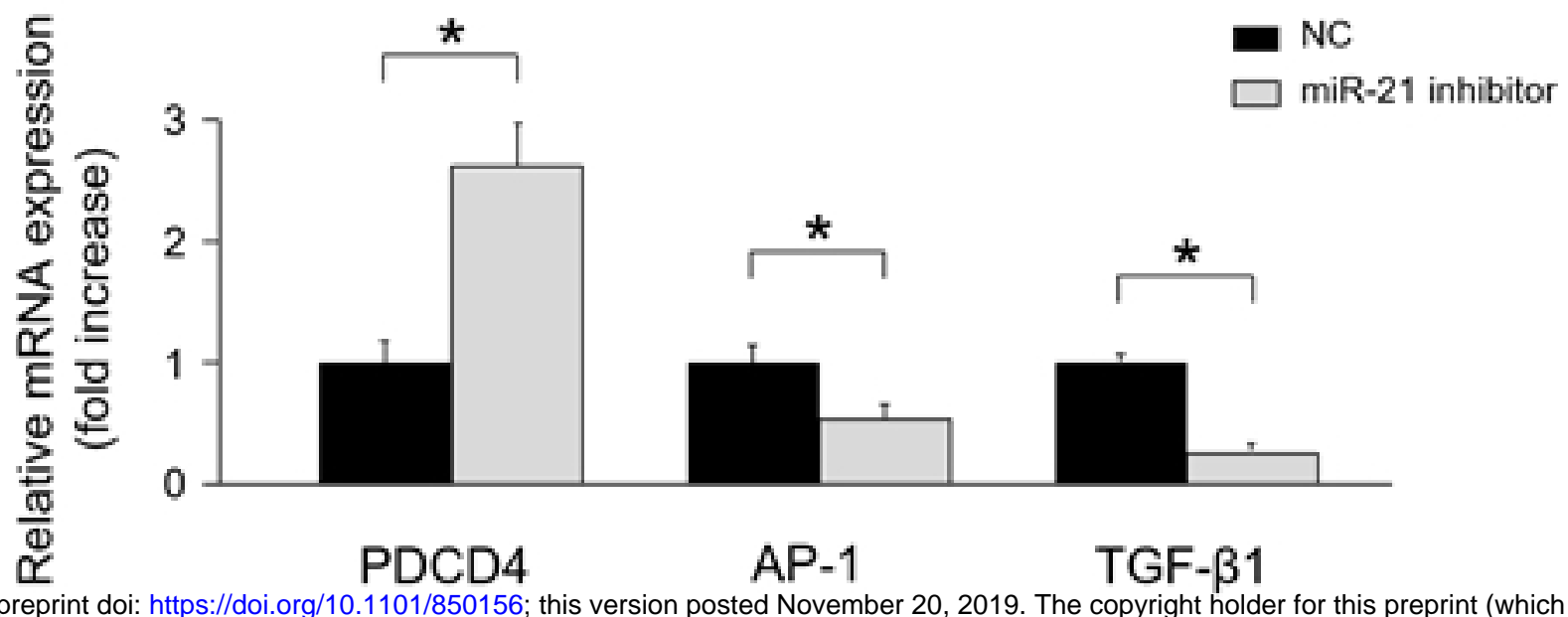
bioRxiv preprint doi: https://doi.org/10.1101/850156; this version posted November 20, 2019. The copyright holder for this preprint (which was not certified by peer review) is the authouable under aCC-BY 4.0 International license.

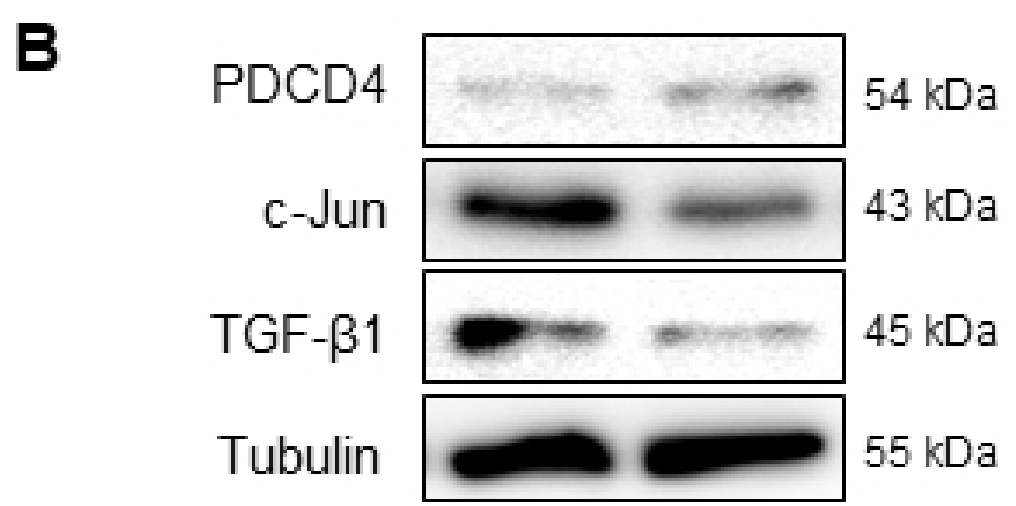

NC miR-21 inhibitor
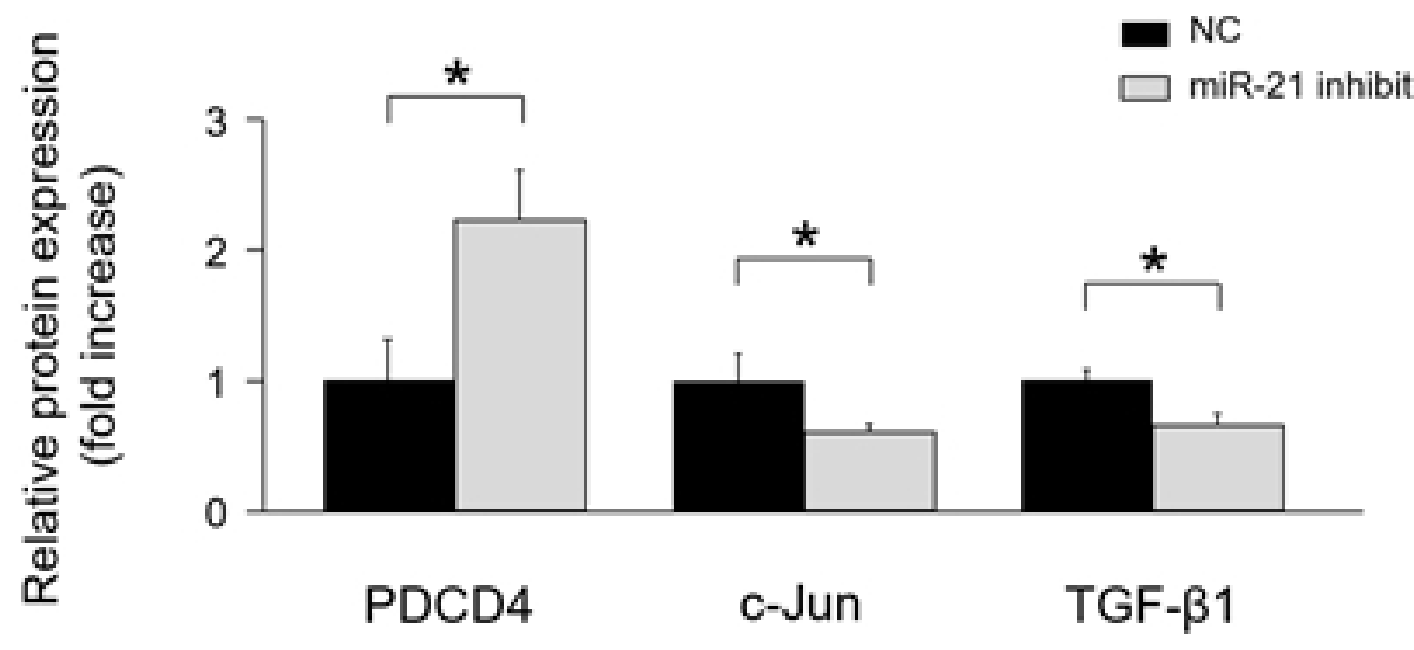

Fig. 5 
Fig. 6

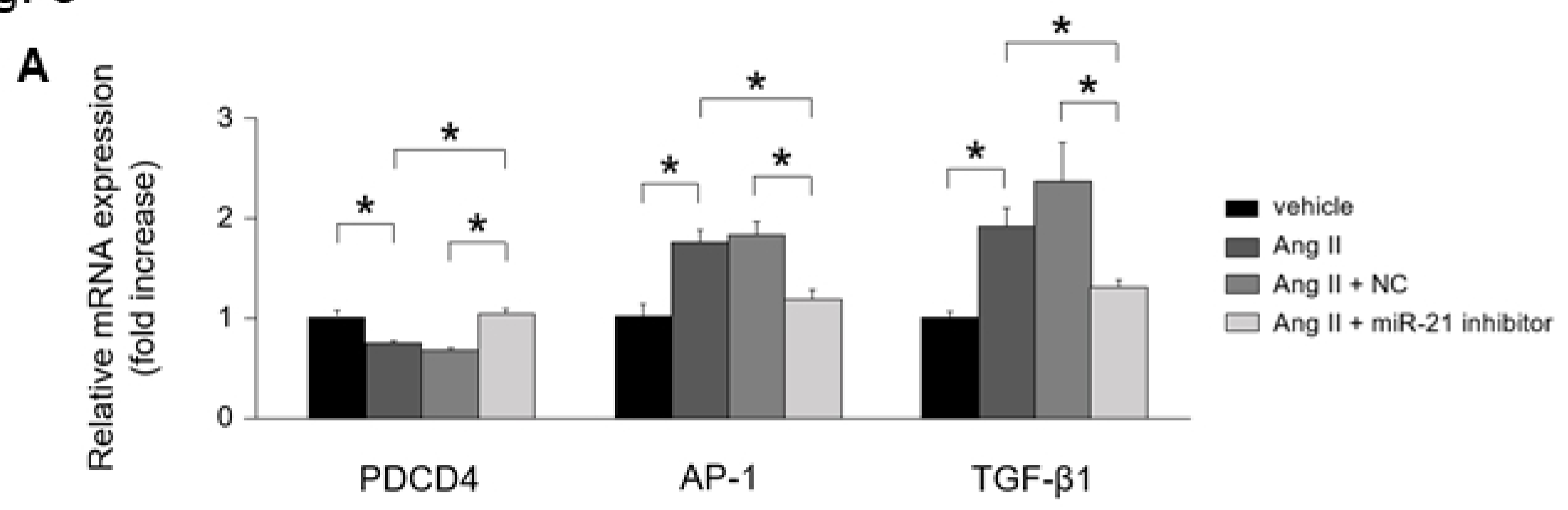

$\mathbf{B}_{\text {b }}$

bioRxiv preprint doi: $\mathrm{h}$ tps//doi.org/10.1101/850156; this version posted Nove mber 20, 2019. The copyright holder for this preprint (which

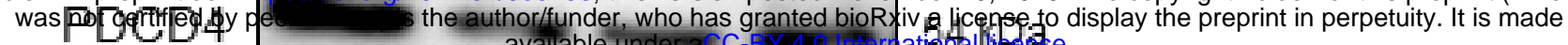

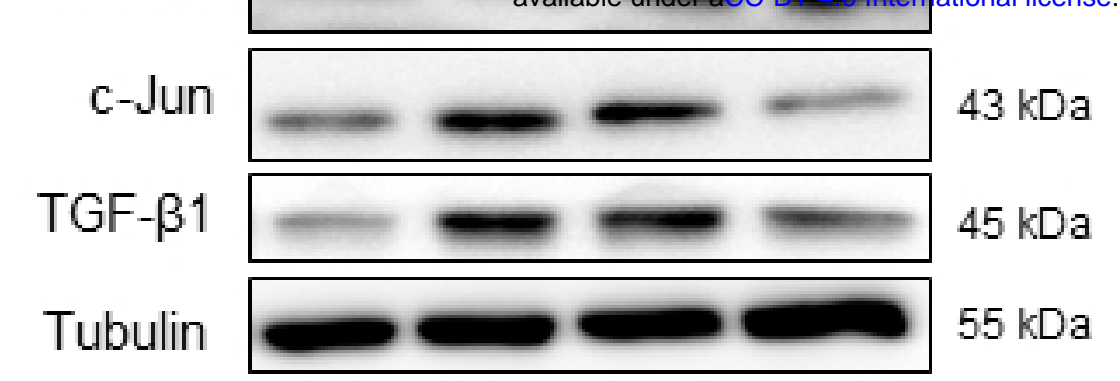

vehicle Ang II Ang II + Ang II+

NC miR-21 inhibitor
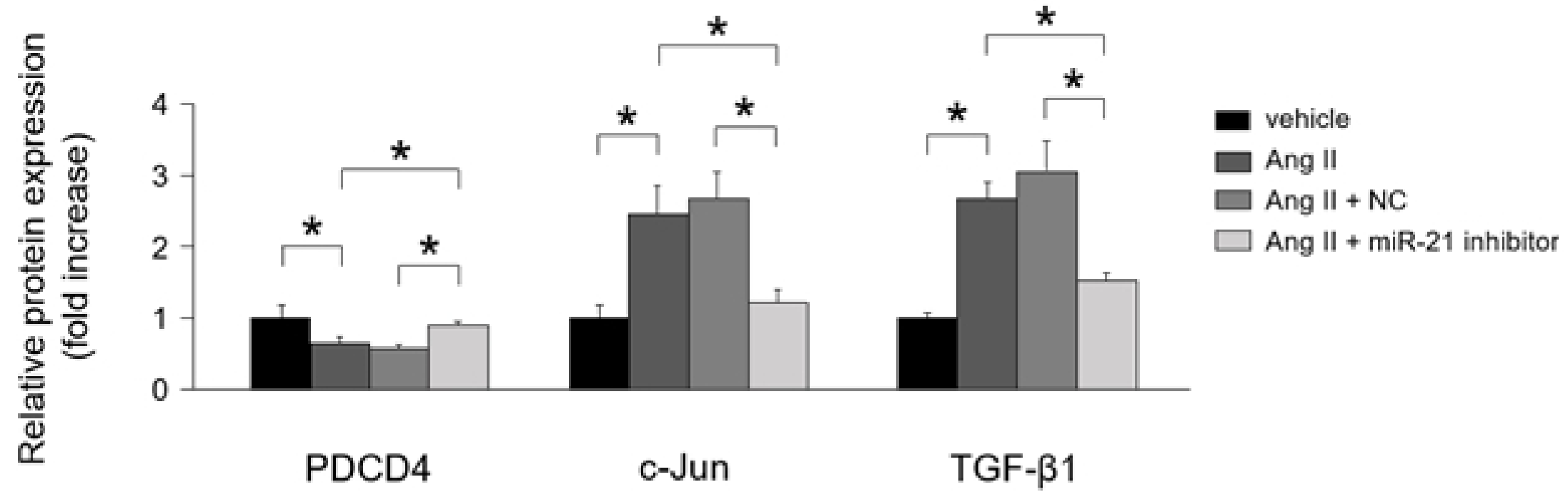

C

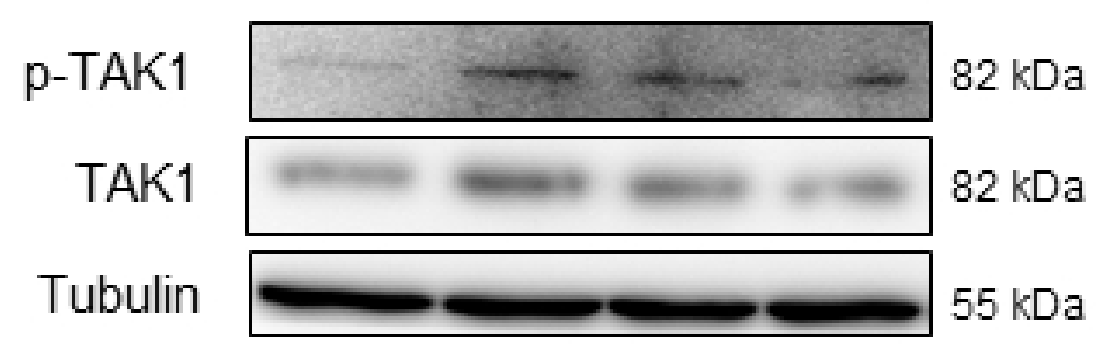

vehicle Ang II Ang II + Ang II + NC miR-21 inhibitor

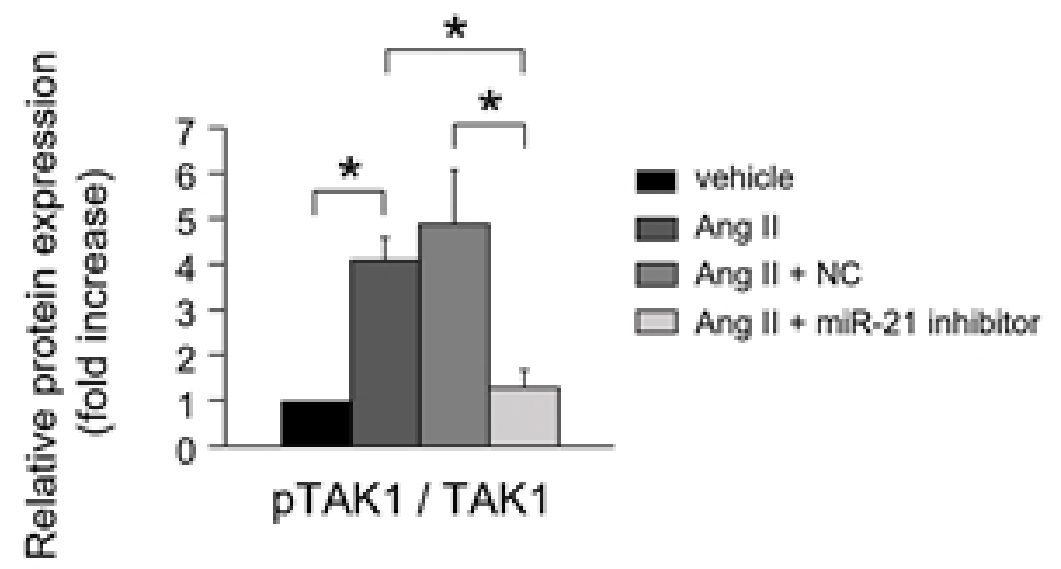

D

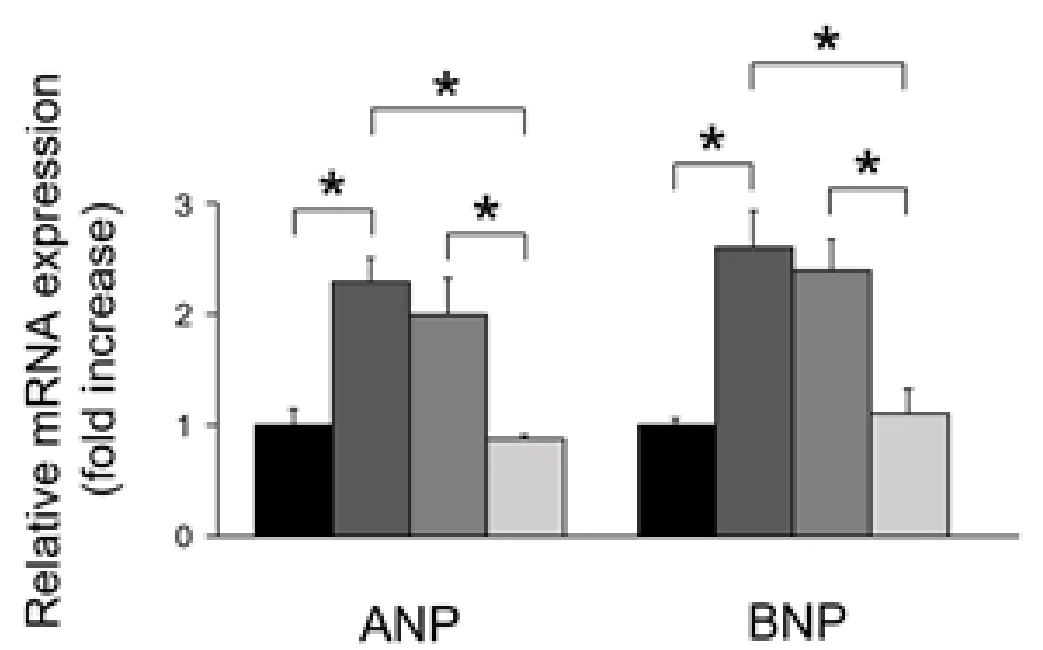

vehicle

$\square$ Ang II

$\square$ Ang II + NC

$\square$ Ang II + miR-21 inhibitor

Fig. 6 
Fig. 7

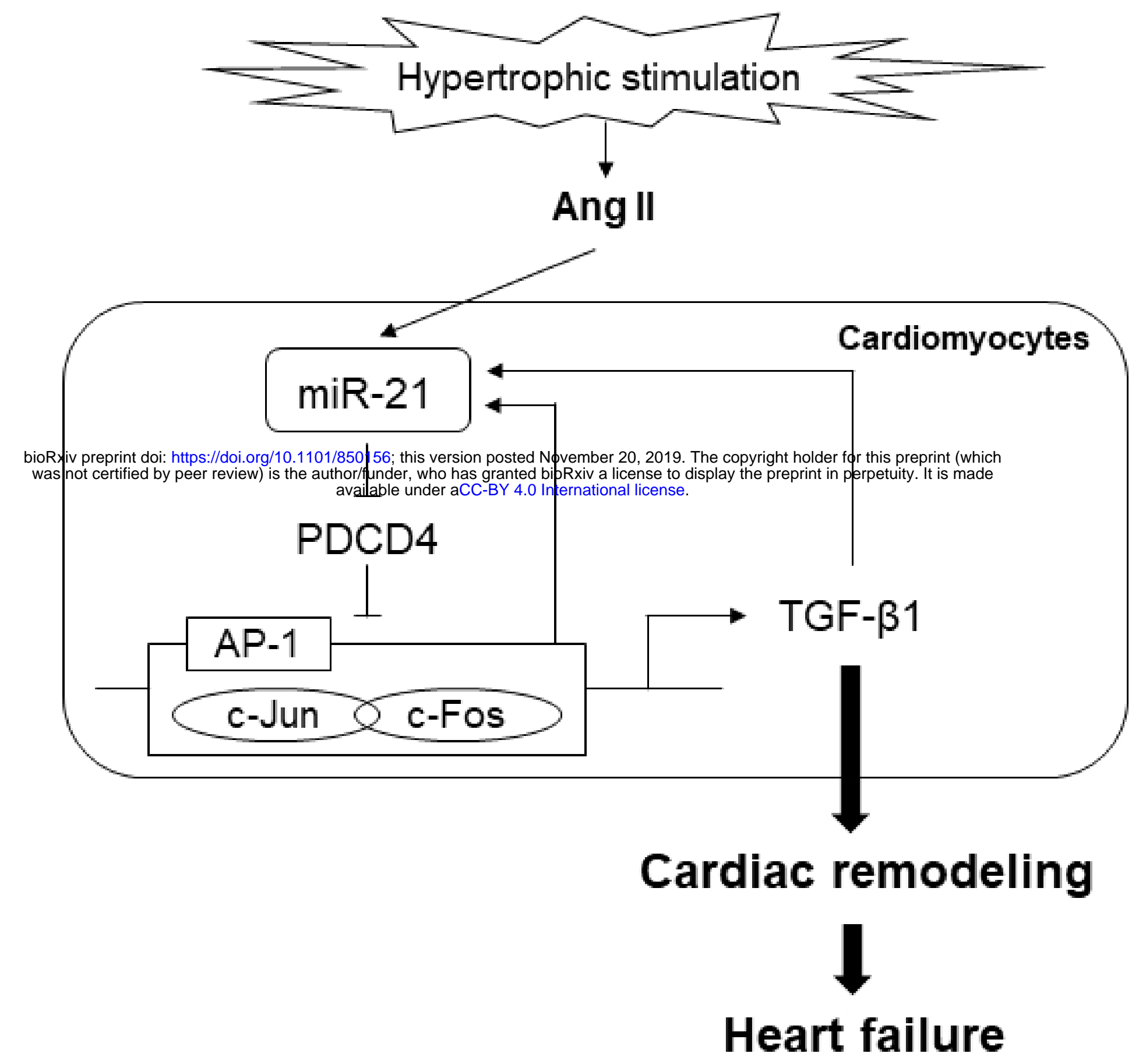

Fig. 7 